This paper has been published as

Ragni, R., Bienen, B., O’Loughlin, C.D., Stanier, S.A., Cassidy, M.J., Morgan, N. (2020). Observations of the effects of a clay layer on suction bucket installation in sand. Journal of Geotechnical and Geoenvironmental Engineering (ASCE), https://doi.org/10.1061/(ASCE)GT.1943-5606.0002217. 


\section{Observations of the Effects of a Clay Layer on Suction-Bucket Installation in Sand}

Raffaele Ragni ${ }^{1}$ now 2

Geotechnical Engineer

Tel: +61 (0) 864881204

Email: raffaele.ragni@uwa.edu.au

Britta Bienen ${ }^{1}$ (corresponding author)

Associate Professor and Lloyd's Register Foundation Chair

Tel: $+61(0) 864884246$

Email: britta.bienen@uwa.edu.au

Conleth D. O'Loughlin ${ }^{1}$

Associate Professor

Tel: +61 (0) 864887326

Email: conleth.oloughlin@uwa.edu.au

Samuel A. Stanier ${ }^{1 \text { now } 3}$

University Senior Lecturer

Tel: +44 (0) 7856009042

Email: sas229@cam.ac.uk

Mark J. Cassidy ${ }^{1 \text { now } 4}$

Professor

Tel: +61 (0) 383446619

Email: mark.cassidy@unimelb.edu.au

Neil Morgan 5

Principal Geotechnical Engineer

Tel: +44 (0) 1224398029

Email: neil.morgan@lr.org 
${ }^{1}$ Centre for Offshore Foundation Systems and Lloyd's Register Centre of Excellence for Offshore Foundations

University of Western Australia

35 Stirling Hwy, Crawley, Perth, WA 6009 Australia

${ }^{2}$ NGI, Norwegian Geotechnical Institute

Level 7/40 St Georges Terrace, Perth WA 6000, Australia

${ }^{3}$ Cambridge University Engineering Department,

Trumpington Street, Cambridge, CB2 1PZ, United Kingdom

${ }^{4}$ Melbourne School of Engineering

The University of Melbourne

Doug McDonell Building, Victoria 3010 Australia

${ }^{5}$ Lloyd's Register EMEA, Kingswells Causeway, Prime Four Business Park, Kingswells, Aberdeen, AB15 8PU, United Kingdom 


\begin{abstract}
Suction buckets are becoming established as a viable foundation solution for offshore wind turbines. In sand, suction-induced seepage flow reduces effective stresses at the skirt tips, which decreases penetration resistance. However, layered seabeds are often encountered in areas of offshore wind farm development. The effect of the presence of a clay layer on the suction-induced seepage flow in the sand layer is not well understood. Therefore in this study, the effects of a clay layer on suction bucket installation in dense sand was investigated by analysing images of a half-bucket installed against a Perspex window captured during tests performed in a geotechnical centrifuge, such that the stress levels are realistic and relevant to field conditions. Installations in sand-over-clay were unproblematic and characterised by deformation of the sand-clay interface, with no clear interruption of the seepage flow. Installations in clay-over-sand were also successful. Uplift of the clay plug was identified as the mechanism to transfer suction to the underlying sand, creating seepage flow and thus facilitating further skirt penetration rather than terminating the installation.
\end{abstract}




\section{Introduction}

Suction buckets are increasingly considered as foundation solutions for offshore wind turbines (OWT) (e.g. in the North Sea at the Borkum Riffgrund 1/2 and Aberdeen Bay sites). Advantages include fast installation (in Aberdeen Bay the installation of the last jacket with $\sim 10 \mathrm{~m}$ diameter suction buckets took 2 hours and 40 minutes (Offshorewind.biz 2018), compared to commonly used monopiles, which take a day or more to install (Lacal-Arántegui et al. (2018)) and practically silent installation, which minimises disturbance to marine fauna.

The concept involves a steel cylinder that is open-ended at the bottom and closed at the top. Initial penetration is achieved through self-weight, which creates a pathway for seepage flow through the soil around the embedded skirt tips. Water is then pumped from the bucket interior, resulting in a differential pressure (referred to as suction) across the bucket lid. For installations in clay suction creates a downward force, which drives the bucket further into the seabed (Houlsby \& Byrne 2005a). In sand, the seepage flow induced by suction - resulting from the relatively high soil permeability - reduces the effective stress below the skirt tips, facilitating installation (Erbrich \& Tjelta 1999, Houlsby \& Byrne 2005b, Andersen et al. 2008, Senders \& Randolph 2009).

Although sandy soils prevail in the shallow waters where offshore wind farms have so far developed, exposure to geological events often causes soil layering, with significant variation of the soil properties both vertically and horizontally (Dove et al. 2016, Cotterill et al. 2017, Sturm 2017). Andersen et al. (2008) noted that the interbedded layers of clay in sand may prevent seepage flow, and hinder the reduction in effective stresses needed for penetration.

Where clay is overlain by sand, suction bucket installation may broadly follow the schematic in Figure 1a. Seepage flow develops when a suction $p_{1}$ is applied, provided the skirt tips remain in the sand layer. As the skirts approach and penetrate the low permeability clay, seepage flow 
may be restricted, which would affect the seepage flow and reduction in effective stresses at the skirt tips (Andersen et al., 2008; Zhu, 2018).

Where sand is overlain by clay, (Figure $1 \mathrm{~b}$ ) sufficient suction $p_{1}$ will cause shearing at the skirtclay interface, facilitating bucket penetration through the clay. However, the clay layer will initially prevent any seepage flow from developing in the underlying sand. Hence, no reduction in effective stresses below the skirt tips is experienced as the bucket advances through the underlying sand, which may hinder installation when high penetration resistance is encountered. However, if the applied suction $p_{1}$ is sufficient to fail the clay plug (i.e. $p_{1} \geq p_{\text {plug }}$ ), clay uplift is expected to occur, such that a suction pressure $p_{2}=p_{1}-p_{p l u g}$ will form in the newly formed gap, which in turn will generate seepage flow (Senders et al. 2007). Reduced scale model tests both in a centrifuge (Tran et al. 2007; Watson et al. 2006; and Senders et al. 2007) and at single gravity (Cotter, 2009) show that installation in sand overlain by a less permeable material is possible. However, the governing mechanisms are not as well understood, such that extrapolation of this performance to seabed profiles beyond the current limits of experience will introduce uncertainty, as discussed for recent case studies (Panayides et al., 2017; Saue et al., 2017). Furthermore, suction installation may alter the soil state within or surrounding the bucket, and such changes may affect in-service performance.

This paper therefore considers the performance of suction buckets in layered seabeds through an experimental study that visualises the effects of a clay layer on suction bucket installation in dense sand, where effective stress reduction through seepage flow around the skirt tip is essential for successful installation. The study aims to:

- Reveal the deformation mechanism and changes in soil state governing suction bucket installation in sand-over-clay and clay-over-sand profiles; 
- Assess the effects of pumping flow rate and thickness of the clay layer on installations in clay-over-sand profiles; and

- Assess the potential for - and the consequences of - any clay plug uplift.

To address these aims, particle image velocimetry (PIV) analyses (Stanier \& White 2013, Stanier et al. 2015) were carried out on images of suction bucket installations in a geotechnical centrifuge. The paper represents the first observation of the effects of a clay layer on suction bucket installation in sand, at relevant stress levels.

\section{Experimental details}

The experiments were conducted using a half-model suction bucket installed using a combination of self-weight and suction assistance adjacent to a window, allowing photography of the bucket interior during installation. The techniques and approach used in the experiments are reported in detail in Ragni et al. (2019), and described in brief in the following sections.

The experimental programme involved eight suction bucket installations, two in sand-overclay $(\mathrm{SoC})$ and six in clay-over-sand $(\mathrm{CoS})$, with the focus placed on the latter as this was considered to have higher potential to be problematic. Jacked installations were also conducted for each soil profile type to provide a basis for assessing the effect of suction installation. Installations in clay-over-sand investigated the role of clay thickness and pumping rate. Table 1 provides a summary of all tests performed and the main characteristics of the soil samples.

\section{Centrifuge and experimental apparatus}

The experiments were performed at $100 \mathrm{~g}$ in the $1.8 \mathrm{~m}$ radius beam centrifuge at The University of Western Australia (Randolph et al. 1991, Randolph \& Gaudin 2017).

Figure 2a shows an overview of the centrifuge set-up. A centrifuge sample container (strongbox) housed a smaller PIV sample box (with inner dimensions of $335 \times 225 \times 300 \mathrm{~mm}$ ), 
which had a $50 \mathrm{~mm}$ thick transparent acrylic window, sufficient to avoid excessive deflection (Haigh \& Madabhushi 2014). The half-model bucket was fabricated from a solid block of aluminium and was anodised, had a diameter $D=50 \mathrm{~mm}$ and skirt length $L=50 \mathrm{~mm}$, i.e. a geometrical aspect ratio $L / D=1$, which is within the range of relevant geometries for shallow water applications (e.g. Borkum Riffgrund 1 and 2, Aberdeen Bay Offshore Wind Farm). The seal between the suction bucket model and the PIV transparent window was obtained with a combination of soft sealant close-cell foam tape on the majority of the interface, and hard rubber at the bucket tips (Ragni et al. 2019). The interface was lubricated prior to each test with petroleum jelly to minimise friction. The penetration resistance and applied suction place significant stresses on the sealant material and the skirt-seal interface. The skirt thickness was $t=2 \mathrm{~mm}$ (i.e. $D / t=25)$, as this was the minimum required to maintain the seal (along the skirt, between skirt and acrylic window) during installation (Ragni et al. 2019). Although lower than typical D/t values, which may be closer to 200, Tran and Randolph (2008) demonstrated that the skirt thickness has only a marginal effect on the suction required during installation.

The model bucket was penetrated adjacent to the window of the PIV sample box using the vertical axis of an electro-mechanical actuator under displacement control (modelling the selfweight installation stage) before holding the load acting at the end of the self-weight installation stage and using a syringe pump to extract fluid from the bucket interior and model (modelling the suction assistance installation stage). An axial load cell with a measurement range of $2 \mathrm{kN}$ was used to maintain a constant vertical load during the suction installation stage. Two 5megapixel machine vision cameras (Allied Vision Technologies Prosilica GC2450C) were positioned opposite the PIV window. As described in Teng et al. (2017) and Ragni et al. (2019), the 'master' camera used an $8 \mathrm{~mm}$ lens to provide a view of the entire window, whereas the 'micro' camera used a $43 \mathrm{~mm}$ lens such that the field of view was restricted to the region around the bucket and the effective resolution was approximately 20 times higher. The cameras 
captured images of the advancing bucket at a frequency of 10 images per mm of bucket penetration. Two LED light panels provided a sufficient and uniform illumination of the PIV window (Teng et al. 2017).

A three-way remotely operated valve (Bienen et al. 2018) on the suction bucket lid (Figure 2b) was used to either allow free flow of fluid across the bucket lid during self-weight installation, or to provide a hydraulic connection to the syringe pump (inner diameter $D_{\text {pump }}=50 \mathrm{~mm}$ ) for suction installation. A $100 \mathrm{kPa}$ Honeywell differential pore-pressure sensor on the bucket lid invert measured the differential pressure across the lid throughout the test.

\section{Soil sample}

As the focus in this paper is the effect of a low permeability clay on suction bucket installation in dense sand, samples were created by combining layers of clay (of near uniform strength) and dense sand. The properties of the kaolin clay and the fine silica sand used to create the samples are summarised in Table 2.

The clay was prepared as a slurry by mixing water and dry kaolin powder at a water content of $\sim 120 \%$, before consolidation in a sample container (larger than the PIV sample container) using a hydraulic press under a vertical stress $\sigma_{\mathrm{v}}^{\prime}=200 \mathrm{kPa}$. The undrained shear strength $s_{\mathrm{u}}$ was assessed from miniature T-bar penetrometer tests performed at single gravity immediately after removing the sample from the hydraulic press. These tests gave an approximately constant $s_{u} \sim$ $39 \mathrm{kPa}$ with depth (adopting a bearing factor, $N_{\mathrm{Tbar}}=10.5$, Martin \& Randolph 2006). After the T-bar penetrometer tests one of the sample container walls was removed to allow clay slices to be cut from the samples and placed in the PIV box at the required depth. To quantify the expected undrained shear strength of the clay layer in each test (due to the varying OCR and average vertical effective stress) Su was calculated using (Ladd et al. 1997): 
$S_{\mathrm{u}}=\sigma^{\prime}{ }_{\mathrm{v}}\left(s_{\mathrm{u}} / \sigma_{\mathrm{v}}^{\prime}\right)_{\mathrm{NC}} \mathrm{OCR}^{\Lambda}$

where the vertical effective stress $\sigma^{\prime}{ }_{v}$ was calculated at the mid-depth of each clay layer (i.e., $h_{\text {clay }} / 2$ in CoS samples, and $h_{\text {sand }}+h_{\text {clay }} / 2$ in SoC samples), the normally consolidated undrained strength ratio was taken as $\left(s_{\mathrm{u}} / \sigma^{\prime}{ }_{\mathrm{v}}\right)_{\mathrm{NC}}=0.15$ (Cocjin et al. 2014, Morton et al. 2014, O'Beirne et al. 2015), and the plastic volumetric strain ratio was taken as $\Lambda=(\lambda-\kappa) / \lambda$, where $\lambda$ is the slope of the normal compression line and $\kappa$ the slope of the unload-reload line. The values of undrained shear strength estimated using Equation 1 for each clay layer are reported in Table 3.

The sand-over-clay samples (SoC_1, SoC_2; Table 1$)$ involved a clay layer $\left(h_{\text {clay }}=70 \mathrm{~mm}=\right.$ $1.5 \mathrm{~L}$ ) resting on a $75 \mathrm{~mm}$ base layer of very dense coarse sand (to optimise use of the finite prepared over-consolidated clay material). A $30 \mathrm{~mm}$ layer of the fine silica sand $\left(h_{\text {sand }}=0.6 L\right)$ was air pluviated over the clay into the PIV box using an automated sand rainer and then saturated (details provided later in the paper). The sand layer was sufficiently thick $\left(h_{\text {sand }}=\right.$ $0.6 L$ ) to allow significant suction-assisted penetration in sand to be observed, and investigate any potential changes in seepage flow as the skirt tips approached the clay layer.

The clay-over-sand samples $\left(\mathrm{CoS} \_1\right.$ to $\mathrm{CoS} \_6$; Table 1) had a $10 \mathrm{~mm}$ thick drainage layer of coarse sand at the bottom of the PIV box, overlain by a layer of geotextile to promote uniform saturation from the base of the sample. The dense, fine silica sand was created by pluviation (as for the sand-over-clay samples) and then saturated. Finally, a clay layer of thickness $h_{\text {clay }}=$ 10,20 or $30 \mathrm{~mm}(0.2,0.4,0.6 \mathrm{~L}$; refer to Table 1$)$ was placed manually on the sand layer. The motivation for a clay thickness $h_{\text {clay }}=0.2 L$ was to assess the effect of introducing a hydraulic barrier in the sand at different pumping rates, whereas the effect of clay thickness $\left(h_{\text {clay }}=0.4 L\right.$ and $0.6 L$ ) was assessed at the same pumping rate. All samples had a height of $175 \mathrm{~mm}$ (i.e. $3.5 L)$ 
The sand was saturated from the base of the sand layer on the laboratory floor with a solution of water and $1.4 \%$ cellulose ether, to obtain a viscosity of $100 \mathrm{cSt}$ (at a temperature of $20^{\circ} \mathrm{C}$, DOV 2002). Matching the fluid viscosity with the centrifuge acceleration of $100 \mathrm{~g}$ allowed the drainage properties to be scaled correctly (Tan \& Scott 1985, Taylor 1987, Dewoolkar et al. 1999, Bienen et al. 2018).

In order to obtain the optimal particle contrast required for high quality PIV analyses, $25 \%$ dyed (black) sand was mixed with $75 \%$ untreated sand. Contrast in the clay layer was achieved by applying black artificial seeding material to the exposed surface of the (white) clay before placing the layer in the PIV box (with the black and white textured clay surface visible in the photos).

Cone penetrometer tests (CPTs) were performed at the testing centrifuge acceleration of $100 \mathrm{~g}$ in each sample using a $7 \mathrm{~mm}$ diameter cone penetrometer, penetrated at $1 \mathrm{~mm} / \mathrm{s}$. Representative profiles of cone tip resistance $q_{\mathrm{c}}$ with depth for sand-over-clay and clay-over-sand samples are provided in Figure 3, and are considered later in the paper to assist in the interpretation of the measured suction and rate of bucket penetration.

\section{Testing procedure}

A jacked test in a sand-over-clay sample (SoC_1) and in a clay-over-sample sample (CoS_1) with the lid vented was included in the experimental programme to provide a basis for comparison with tests in samples with equivalent layering but where suction-assisted installation was employed. The penetration velocity in these jacked tests was $0.057 \mathrm{~mm} / \mathrm{s}$, consistent with that adopted in sand tests reported in Ragni et al. (2019).

The remaining suction-assisted installation tests comprised two main stages: (i) initial selfweight penetration, and (ii) suction-assisted penetration. 
Although self-weight penetration is a load-controlled event in practice, displacement control using the same penetration velocity as in the jacked tests (i.e. $0.057 \mathrm{~mm} / \mathrm{s}$ ) was chosen to facilitate comparison between the tests. A self-weight penetration of $z_{\mathrm{s}-\mathrm{w}} / L=0.2$ was adopted for the sand-over-clay case (SoC_2, matching the self-weight embedment in the sand tests reported in Ragni et al. 2019). In clay-over-sand, it was assumed that the bucket self-weight would cause the skirts to penetrate through the clay layer into the underlying sand, regardless

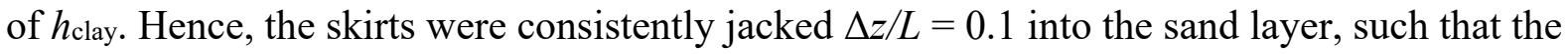
suction-assisted installation commenced at the same embedment depth (relative to the top of the sand layer).

Once the target self-weight embedment was achieved (see Table 3), the actuator was switched to load control to maintain the vertical load $V_{\mathrm{s} \text {-w }}$ (measured at the end of the self-weight installation phase, see Table 3) during the suction-assisted installation phase of the test. The valve was then adjusted to hydraulically connect the bucket to the syringe pump, which was then activated at a constant pumping flow rate $q_{\text {pump }}$ (see Table 1 for the pumping flow rates adopted in each test). As discussed in Bienen et al. (2018), the penetration rate at model scale with the pore fluid viscosity matching the centrifugal acceleration corresponds to that in the prototype with water as a pore fluid, such that the overall installation duration is realistic. The average pumping flow rate was thus selected to achieve a realistic installation duration, and then varied to investigate the effect that this might have on the soil response during suction bucket installation.

The entire test sequence was performed at $100 \mathrm{~g}$ without stopping the centrifuge.

\section{PIV post-analysis}

Particle image velocimetry (PIV) analyses were performed using GeoPIV-RG (Stanier \& White 2013, Stanier et al. 2015) on the high-resolution images obtained using the 'micro' 
camera (field of view shown in Figure 2c) at different normalised depths $z / L$ and for an incremental bucket penetration $\Delta z=0.5 \mathrm{~mm}$.

The array used to analyse the soil domain was formed using 50-pixel square subsets equally spaced every 25 pixels (i.e. with initial overlapping of 25 pixels). The automatic reference image updating scheme described in Stanier et al. (2015) was utilised to automatically track the soil displacements throughout the whole image series, whilst ensuring maximal correlations with the adoption of stringent convergence criteria. All the PIV analyses adopted a minimum correlation coefficient tolerance, $C C_{Z N C C}=0.75$ (as recommended in Stanier et al. 2015, where $0=$ no correlation and $1=$ perfect correlation $).$

\section{Results and discussion}

Table 3 summarises the main results from the tests, including the embedment achieved after each installation stage, the contribution (to the final embedment) of plug heave and the volume of soil displaced by the advancing skirts. Complete embedment was not achieved in every test as noted in the footnotes to Table 3. Further details and interpretation of these results, including observations from the PIV analyses, are provided in the following sections.

\section{Sand over clay}

\section{Deformation mechanisms and changes in soil state}

Figures 4 and 5 show the total shear $\gamma_{\mathrm{s}}$ (LHS) and total volumetric $\varepsilon_{\mathrm{V}}$ strain distribution (RHS; positive $=$ compression) for jacked (Figure 4) and suction-assisted installation (Figure 5) in sand-over-clay (SoC_1, SoC_2) due to incremental penetrations of $\Delta z=0.5 \mathrm{~mm}$ at increasing depths, $z$ PIV $/ L=0.3,0.6$ and 0.9 .

The two cases are similar initially $(z / L \leq 0.3)$, with prevalent shearing along the skirt, and below the skirt tips. In the case of suction-induced installation, inverted ' $\mathrm{V}$ ' shear bands propagate 
towards the inside of the bucket (Figure 5a), similar to observations from installation in dense sand (Ragni et al. 2019). However, as penetration advances and the skirt tips reach the sandclay interface $(z \mathrm{PIV} / L=0.6)$, the underlying clay layer deforms. As the clay has a lower strength than the overlying sand, the inverted ' $\mathrm{V}$ ' shear bands disappear and rapid advancement of the bucket is observed, which is accompanied by localised shear strains along the skirts (Figures $4 b, c ; 5 b, c)$.

The above behaviour is reflected in the volumetric strain distributions, where the majority of the sand plug does not undergo any significant change throughout the installation. Minor compression is observed under the skirt tips at $z$ PIV $/ L=0.3,0.6$ (Figure $4 \mathrm{~d}$,e; $5 \mathrm{~d}$,e), whereas compression of the clay material is more visible at $z \mathrm{PIV} / L=0.9$ (Figure $4 \mathrm{f}, 5 \mathrm{f}$ ). The sand-clay interface experiences significant deformation, as also documented for other foundations penetrating through sand over clay, with a sand frustum being pushed ahead of the foundation into the clay (Meyerhof (1974) on shallow footings, and Craig \& Chua (1990), Teh et al. (2008), Qiu \& Grabe (2012) and Lee et al. (2013a), among others, on spudcan foundations). However, unlike these examples, in these bucket penetration experiments the sand is pushed down by the skirt tips rather than the entire foundation cross-section. An important consequence is that the bucket skirts did not come in contact with the clay layer. Thus, it can be deduced that for the suction-assisted case (SoC_2) the seepage flow was never fully blocked. Differences in radial stresses induced by jacked and suction-assisted installation, respectively, are reflected in the soil strain and deformation fields (comparing Figures 4 and 5).

\section{Suction and penetration rate profiles}

The normalised suction pressure $p / \gamma^{\prime} D$ (where $\gamma_{s}^{\prime}$ is the submerged unit weight of the sand) measured at the lid invert in SoC_2 (Figure 6a) increased during the initial penetration stage (consistently with development of ' $\mathrm{V}$ ' shear bands in Figure 5a), but reduced as the sand-clay 
interface was approached. The normalised penetration rate of the bucket, $(\dot{z} A)_{\text {bucket }} / q_{\text {pump }}$ (Figure $6 \mathrm{~b}$, where $A$ is the internal cross-sectional area of the half-model bucket $=\pi D_{\mathrm{i}}^{2} / 8$ ) initially reduces $(z / L \leq 0.4)$ due to the constant applied pumping flow rate despite increasing penetration resistance in the sand layer but then increases as the skirts approach and penetrate through the clay layer.

According to the theory of volume continuity the fluid volume pumped out by the syringe pump Volpump should equal the sum of (i) the volume of water displaced by the penetrating bucket Volbucket, (ii) the seepage volume Vol $_{\text {seep, }}$ (iii) and a 'system' volume due to water compressibility $\operatorname{Vol}_{\text {sys }}$ (usually negligible):

$V o l_{\text {pump }}=V o l_{\text {bucket }}+V o l_{\text {seep }}+V o l_{\text {sys }}$

The theory is valid provided the increasing bucket penetration resistance is continuously overcome through the generation of suction. Furthermore, if the clay layer prevents seepage (i.e. $V o l_{\text {seep }}=0$ ), the normalised penetration rate should be constant and equal to unity.

However, for SoC_2 the normalised penetration rate, $(\dot{z} A)$ bucket $q_{\text {pump }}>1$ in the clay layer (for $z / L>0.6$ ). The CPT profile (Figure $3 b$ ) offers an explanation in this regard, showing that the cone tip resistance, $q_{\mathrm{c}}$, at the bucket self-weight embedment $\left(z_{\mathrm{s}-\mathrm{w}} / L=0.2\right)$ is larger than in the clay $\left(q_{\mathrm{c}}\right.$ at $\left.0.6<z / L<1\right)$. This suggests that the bucket self-weight $V_{\mathrm{s}-\mathrm{w}}$ would be sufficient to penetrate through the clay layer. However, an extra vertical driving force $p A$ is still being provided through the application of suction $\left(p / \gamma_{s}^{\prime} D>0\right)$ which, in combination with $V_{\text {s-w, }}$ causes the bucket penetration rate to exceed the pumping flow rate $\left((\dot{z} A)\right.$ bucket $\left./ q_{\text {pump }}>1\right)$.

This results in over-pressure (rather than suction) in the inner compartment $\left(p / \gamma^{\prime}{ }_{s} D<0\right.$ at $z / L \sim 0.7)$, because the volume of fluid displaced by the advancing bucket is greater than the volume pumped by the syringe, causing the penetration rate to decrease again. The soil plug 
responds in an undrained fashion, such that the suction bucket and soil plug behave much like a rigid embedded foundation, transferring the failure mechanism to the skirt tip level (Figure 7, SoC_2, 'macro' camera view to fully capture the mechanism). A different response is observed in Figure 8 for the jacked installation (SoC_1, 'macro' camera view), as the free flow of fluid resulted in a different drainage response within the soil plug. At $z / L \sim 1.15$, equilibrium between the resultant vertical force $\left(V_{\mathrm{sw}}+p A\right)$ and the bucket resistance is achieved for SoC_2 (i.e. $p / \gamma^{\prime}{ }_{s} D=0$ ), followed shortly by contact of the lid with the soil surface at $z_{\text {fin }} / L=1.19$. The jacked installation (SoC_1) achieved lid contact at $z$ fin $/ L=1.11$ (Table 3).

\section{Summary, sand over clay}

In summary, the results of the installations in sand-over-clay are in line with the expected behavior (considering the CPT profiles), with suction-assisted installation (SoC_2) proving to be unproblematic for the test conditions considered. The final penetration depth was greater than the skirt lengths for both jacked and suction-assisted installations $\left(z_{\mathrm{fin}} / L=1.11\right.$ and 1.19 , Table 3), which is consistent with the downward migration of the sand-clay interface. Further effort in sand-over clay seabed profiles should focus on establishing if installation is also straightforward for higher clay strengths (as lower sand densities are likely to be less problematic).

\section{Clay over sand}

\section{Deformation mechanisms}

Figure 9 shows the progression of the deformation mechanism (resultant displacement contours) associated with the jacked installation in clay over sand $\left(\mathrm{CoS} \_1, h_{\text {clay }}=0.2 L\right)$. At $z \mathrm{PIV} / L=0.15$ (Figure 9a) a shallow mechanism is observed within the clay layer. Clay material is squeezed laterally as the skirts approach the stronger underlying sand. As penetration 
continues into the sand $(z \mathrm{PIV} / L=0.30$; Figure $9 \mathrm{~b})$, a transition to a more localised mechanism around the skirt tips is observed, in line with observations from Ragni et al. (2019) for installation in dense sand.

During jacked installation, the soil displaced by the skirt tips is equally distributed inside and outside the bucket (see inset in Figure 9c). The final soil plug heave $h_{\text {plug }} / L \sim 0.05$ recorded at the final penetration of $z$ fin $/ L=0.95$ (Figure A1) can be therefore attributed to the soil displaced by the advancing skirts entering the bucket (quantified in $h_{\text {skirt }} / L \sim 0.09$, Table 3 ), rather than dilation of the dense sand. In fact, the definition of a dilation contribution, $h_{\mathrm{di}} / L=\left(h_{\text {plug }}\right.$ $\left.h_{\text {skirt }}\right) / L=-0.04$, reveals that the sand might have undergone some minor contraction in volume.

Figure 10 shows the suction-assisted installation with medium pumping flow rate $\left(q_{\text {pump }}=235.62 \mathrm{~mm}^{3} / \mathrm{s}, \operatorname{CoS} \_3\right)$ in terms of normalised displacement contours (LHS, Figure 10a,b,c) and total shear strain distribution (RHS, Figure 10d,e,f). In the early stages of suctionassisted penetration $(0.3<z / L<0.45)$, the clay layer significantly reduces seepage flow, and suction simply creates an additional vertical driving force, $p A$. The absence of seepage flow through the underlying sand plug translates to an approximately constant normalised penetration rate $(\dot{z} A)_{\text {bucket }} / q_{\text {pump }}$ (Figure 11b). Assuming there is no seepage flow the normalised penetration rate should be equal to unity (Bienen et al. 2018), although in this case it is slightly lower which indicates that there is either minor seepage through the clay layer or other losses in the system. However, this is of no real consequence as the purpose of Figure 11 is to assess relative comparisons between tests.

However, at $z \operatorname{PIV} / L=0.45$ (Figure 10a, Figure10d), the formation of a gap at the clay-sand interface can be observed, which spells the beginning of the clay plug uplift. The suction pressure required to lift the plug, $p_{1}=p_{\text {plug }}$ (Figure $1 \mathrm{~b}$ ) can be calculated by (Senders et al. 2007): 
$p_{\text {plug }}=\left(\gamma^{\prime}{ }_{c}+4 / D_{\text {i }} \alpha s_{\mathrm{u}}\right) h_{\text {clay }}$

where $\gamma_{c}^{\prime}=7.5 \mathrm{kN} / \mathrm{m}^{3}$ is the submerged unit weight of the clay, $D_{\mathrm{i}}=46 \mathrm{~mm}$ is the internal diameter of the model bucket, and $\alpha$ is the interface friction ratio (selected as the inverse of the sensitivity (Anderson et al. 2005), i.e. $\alpha=0.4$ ). The theoretical value - adjusted for the half model geometry in these tests - of $p_{\text {plug }} /\left(\gamma_{\mathrm{s}}{ }^{\prime} D\right)=0.27$ underestimated the experimental $p / \gamma^{\prime}{ }_{s} D$ $\sim 0.50$ for CoS_3 at $z / L=0.46$ (Figure 11a), when complete propagation of the fracture was observed (Figure A2). On one hand, such difference can be explained by the uncertainties related to the homogeneity of the clay layer in terms of strength and thickness, as well as the assumed value of $\alpha=0.4$. On the other hand, the difficulty associated with the identification of the exact moment when the fracture fully propagates (which occurs extremely rapidly in a centrifuge environment) in the experiment should be considered.

As explained in Senders et al. (2007), any increase in $p_{1}$ above $p_{\text {plug }}$ translates to suction $\left(p_{2}=p_{1}\right.$ $-\underline{p}$ plug, Figure 1b) and the generation of seepage flow in the sand. Given the constant pumping flow rate applied in the experiments, this results in a reduction in the penetration rate $(\dot{z} A)_{\text {bucket }} / q_{\text {pump }}$ (Figure 11b). Associated with the opening of the gap at the clay-sand interface is an irregular overburden pressure acting on the underlying sand, which causes the asymmetric deformation mechanism (evident in Figure 10a and b).

At $z$ PIV $/ L=0.60$ (Figure $10 \mathrm{~b}, \mathrm{e}$ ), the gap has visibly developed. Rather than moving upwards, as postulated by Senders et al. (2007), the clay plug is rotating, which is likely due to asynchronous failure at the clay-skirt interface.

As the clay plug rotates, a fluid channel eventually opens along the right-hand-side skirt (Figure A3), such that a differential pressure between the lid invert and the surface of the sand layer (i.e. $p_{1}-p_{2}$ ) no longer exists. At $z$ PIV $/ L=0.75$ (Figure 10c, Figure 10f) the clay plug comes to rest on the underlying sand (although a minor gap is still visible), since the pressure $p_{2}$ has been 
dissipated. The deformation mechanism is now symmetric, and the installation can be compared to a sand-only case (Ragni et al. 2019).

\section{Changes in soil state}

Figure 12 presents the total volumetric strain distribution for the installation performed with a medium pumping flow rate $\left(q_{\text {pump }}=235.62 \mathrm{~mm}^{3} / \mathrm{s}, \mathrm{CoS}_{-} 3\right)$. Initially $(z \mathrm{PIV} / L=0.45$, Figure $12 a)$, the absence of any relevant volumetric expansion in the sand plug is consistent with the extremely low expected seepage flow (i.e. minimal $p_{2}$ ). The minimal plug heave development is consistent with the observed negligible sand dilation, and the amount of soil entering the bucket (inset Figure 10a, comparable to inset Figure 9c for the jacked installation). Significant dilation is observed across the clay-sand interface, flagging an imminent fracture.

As penetration continues $(z \mathrm{PIV} / L=0.60,0.75$; Figure $12 \mathrm{~b}, \mathrm{c})$ volumetric expansion is experienced at the crown of the inverted ' $\mathrm{V}$ ' mechanism within the sand plug. A plug heave $h_{\text {plug }} / L=0.17$ at the final penetration $z_{\text {fin }} / L=0.8$ was recorded (Figure A4). The equivalent volume of soil displaced by the skirts at $z \mathrm{fin} / L=0.8$ that entered the bucket is quantified as $h_{\text {skirt }} / L=0.12$ (assuming that all the soil displaced by the skirts enters the bucket during suctionassisted installation, but only half during self-weight installation; see insets Figure 10). Thus, it can be concluded that a limited contribution to plug heave arises from sand dilation (estimated in $\left.h_{\mathrm{dil}} / L=\left(h_{\text {plug }}-h_{\text {skirt }}\right) / L=0.05\right)$, as a result of seepage flow and shearing of the sand along the skirts. These contributions can be used to estimate the dilation experienced by the sand layer, since the volumetric strains can be approximated as $\varepsilon_{v} \sim h_{\mathrm{dil}} / z_{\mathrm{fin}}=6 \%$. Although qualitatively comparable to installations in sand only (Ragni et al. 2019), in the layered soil the limited seepage flow ( $p_{2} \sim 0$ in the early stage of suction-assisted installation) prevented sustained critical gradients and localised piping from developing, leading to lower final volumetric strains than in sand only (which were in the range of 8-11\%, Ragni et al. 2019). 


\section{Effect of pumping flow rate}

The effect of pumping flow rate on suction bucket installation in clay-over-sand was investigated in three tests $\left(\mathrm{CoS} \_2,3,4\right)$ across which the pumping flow rate was varied by one order of magnitude $\left(q_{\text {pump }}=117.81,235.62,1178.1 \mathrm{~mm}^{3} / \mathrm{s}\right)$. Generally, higher pumping flow rates led to larger and faster (in absolute terms of penetration rate, $\dot{z}$ ) penetration, as already reported in Ragni et al. (2019) for installation in sand. Although the test with the highest pumping flow rate $\left(\mathrm{CoS} \_4\right)$ stopped at $z$ fin $/ L=0.72$ due to sudden failure of the soft sealant at the model-window interface, extrapolating the normalised penetration rate (Figure 11b) suggests that installation would have continued until the lid made contact with the soil plug.

Figure 13 compares the soil resultant displacement contours for the three tests with increasing $q_{\text {pump }}\left(\mathrm{CoS} \_2,3,4\right.$ in Figure 13a,b,c respectively) at $z$ PIV $/ L=0.60$. A different clay plug response is observed in each test: uplift for low $q_{\text {pump }}\left(\mathrm{CoS} \_2\right.$, Figure 13a), rotation for medium $q_{\text {pump }}\left(\mathrm{CoS} \_3\right.$, Figure 13b), and combined uplift/rotation for high $q_{\text {pump }}\left(\mathrm{CoS} \_4\right.$, Figure 13c). This may be influenced by slight inhomogeneities in the soil properties and geometry of the clay plug. The deformation mechanisms in sand appear to be affected by the different clay plug response. Partial plug contact with the sand $\left(\mathrm{CoS} \_3\right.$, Figure $\left.13 \mathrm{~b}\right)$ results in the most pronounced asymmetry, as this is likely to provide an irregular overburden pressure, which contrasts with the other two cases.

A much larger clay plug uplift was observed in the test with the lowest pumping flow rate (CoS_2, Figure 13a). This is in agreement with Senders (2008), who demonstrated that a slow installation process (and a high permeability ratio $k_{\text {sand }} / k_{\text {clay }}$ ) can increase the plug uplift, as the water inflow inside the gap will determine the extent to which the clay plug is uplifted. Although high $q_{\text {pump }}$ generates higher suction in the gap, $p_{2}=p_{1}-p_{\text {plug }}\left(p_{2, \text { high }}=1.32 p_{2, \text { low }}\right)$, the resulting installation process is too fast for a large volume of water, $V_{\text {ol }} l_{\text {seep }}$, to be drawn into 
the gap. Assuming that the test with high pumping flow rate has an initial penetration rate that is ten times higher than the test with low pumping flow rate, the seepage volume for the former case is estimated as $\sim 13 \%$ of the latter.

Uplift of the clay plug in CoS_2 (low $q_{\text {pump }}$ ) progressed until the bucket lid touched the plug. At this point, the direct contact between the clay plug and the valve interrupted the flow (Figure A5), causing a reduction in suction that allowed the plug to collapse on the underlying sand. The event is clearly visible in Figure $11 \mathrm{a}$ at $z / L=0.66$. However, interruption of flow, represented by the drop in $p / \gamma_{s}^{\prime} D$, did not result in premature termination of the penetration. Rather, the plug collapse allowed for a sudden increase in suction pressure from $p_{2}$ to $p_{2}+p_{\text {plug, }}$ resulting in a spike in the normalised penetration rate to $(\dot{z} A)_{\text {bucket }} / q_{\text {pump }} \sim 2$. However, full installation could not be achieved, as the increased seepage flow in the sand quickly resulted in refusal of the suction bucket at $z$ fin $/ L=0.70$ (Figure 11b), similar to Ragni et al. (2019) for tests in dense sand at a low pumping rate.

\section{Effect of clay layer thickness}

The effects of a thicker clay layer $\left(h_{\text {clay }}=0.4,0.6 L\right)$ on suction bucket installation were investigated in $\mathrm{CoS}$ 5 5 and $\mathrm{CoS} \_6$. Suction-assisted penetration commenced when the skirts penetrated $0.1 L$ into the sand layer (i.e. $z_{\mathrm{s}-\mathrm{w}} / L=0.5$ and 0.7 for CoS_ 5 and 6 respectively) as the effect of the overlying clay layer on the response in the underlying sand was the focus of the investigation, and suction bucket installation in clay is well understood. The vertical load at $0.1 L$ in the sand layer was then held constant as $V_{\mathrm{s}-\mathrm{w}}$, which led to larger self-weight load with increasing $h_{\text {clay }}$ (see $V_{\text {s-w }}$ in Table 3 for CoS_3, 5, 6), but allowed for consistency of the self-weight embedment.

In both tests with increased clay thickness the deformation mechanism while penetrating the clay layer was mainly localised around the skirt tips, and minor plug heave was observed at the 
end of the self-weight stage $\left(h_{\text {plug }} / L \sim 0.03\right.$ at $z_{\mathrm{s}-\mathrm{w}} / L=0.5$ for CoS_5, and $h_{\mathrm{plug}} / L \sim 0.05$ at $z_{\mathrm{s} \text { - }}$ w/L=0.7 for CoS_6).

A medium pumping flow rate, $q_{\text {pump }}=235.62 \mathrm{~mm}^{3} / \mathrm{s}$, was used for the suction-assisted stage. Figure 14 compares the resultant soil displacement contours for the three tests with increasing $h_{\text {clay }}=0.2,0.4,0.6 L\left(\mathrm{CoS} \_3,5,6\right.$ in Figure $14 \mathrm{a}, \mathrm{b}, \mathrm{c}$ respectively $)$ at $z \mathrm{PIV} / L=0.75$. A twofold increase in clay thickness $\left(h_{\text {clay }}=0.4 L\right.$, CoS_5, Figure $\left.14 \mathrm{~b}\right)$ shows a response comparable to $h_{\text {clay }}=0.2 L\left(C o S \_3, q_{\text {pump }}=235.62 \mathrm{~mm}^{3} / \mathrm{s}\right.$, Figure $\left.14 \mathrm{a}\right)$ during suction-assisted installation. Inverted ' $\mathrm{V}$ ' shear bands propagating from the skirt tips characterise the deformation mechanism, with prevalent inflow of material inside the bucket. A threefold increase in clay thickness $\left(h_{\text {clay }}=0.6 L\right.$, CoS_6, Figure $\left.14 \mathrm{c}\right)$ also resulted in the development of inverted 'V' shear bands after the syringe pump was activated at $z_{\mathrm{s}-\mathrm{w}} / L=0.7$. However, these were confined to the sand layer and did not expand to the clay above, such that the inverted ' $\mathrm{V}$ ' became less pronounced as the clay thickness increased (penetration in sand was limited to $0.6<z / L<1$ ).

The normalised penetration rate for CoS_5 $\left(h_{\text {clay }}=0.4\right)($ Figure $11 \mathrm{~b})$ is initially approximately constant (for $0.5<z / L<0.65$ ), but reduces from $z / L \sim 0.65$, at which point discoloured fluid (i.e. fluid mixed with clay) appeared above the soil plug (Figure A6). This is considered to be the result of seepage occurring along the skirts and/or through cracks in the clay (a possibility proposed by Senders et al. 2007). The fracture at the clay-sand interface visible in Figure 14b (and Figure A7) fully propagated when $p / \gamma^{\prime}{ }_{S} D \sim 0.87$ at $z / L=0.76$ (relative to the calculated value of $p_{\text {plug }} / \gamma_{s}^{\prime} D=0.54$ (Equation 3), i.e. underestimated by $\sim 38 \%$ ). When contact of the lid against the clay plug was achieved (Figure A8) at $z$ fin $/ L=0.86$, a final plug heave $h_{\text {plug }} / L=0.13$ was measured, which included a minor water gap $(<0.01 L)$ at the clay-sand interface. As for $h_{\text {clay }}=0.2 L\left(\mathrm{CoS} \_3\right)$, a reduction of the plug heave was observed when pumping was stopped and the clay plug came to rest on the underlying sand. 
The constant normalised penetration rate for CoS_6 in Figure $11 \mathrm{~b}$ confirms the absence of any seepage flow through the thick clay layer $\left(h_{\text {clay }}=0.6 L\right)$ during suction-assisted installation. No clay plug uplift was observed, since the measured suction never reached the predicted $p_{\text {plug }} / \gamma^{\prime}{ }_{s} D=0.86$ required for clay plug uplift. The final installation depth of $z_{\text {fin }} / L=0.92$ (contact lid-surface) was larger than the tests with $h_{\text {clay }}=0.4\left(z_{\mathrm{fin}} / L=0.86, \mathrm{CoS} \_5\right)$, and $h_{\text {clay }}=0.2\left(z \mathrm{fin} / L=0.8, \operatorname{CoS} \_3\right)$. The final plug heave $h_{\mathrm{plug}} / L=0.09$ was the smallest across the three clay thicknesses investigated, due to (i) reduced suction-assisted installation, (ii) negligible seepage flow through the sand, which limited volumetric expansion, and (iii) minimal clay plug disturbance caused by suction.

\section{Conclusions}

The effects of a clay layer on suction bucket installation in dense sand were investigated through a visual study in a geotechnical centrifuge. Particle image velocimetry (PIV) analyses conducted on images captured during suction bucket installations revealed the following:

- Installations in sand-over-clay were relatively straightforward, as expected. Jacked and suction-assisted installations resulted in similar mechanisms overall, characterised by high shear strains along the skirts and limited volume change within the soil plug. Seepage flow was maintained when the skirt tips reached the clay layer, due to downward migration of the sand-clay interface. Further investigation should focus on establishing the response when the clay is more competent (i.e. stronger and stiffer);

- Installations in clay-over-sand were also successful. The clay layer represented an effective blockage for seepage flow until clay plug uplift (detachment at the clay-sand interface) occurred. The results revealed that clay plug uplift allows suction to be transferred to the underlying sand layer. This has the effect of reducing the tip resistance through seepage flow, despite the overlying (relatively) impermeable layer, easing 
installation in the dense sand layer. The deformation mechanism was comparable to installations in sand only, although characterised by less volumetric expansion of the sand plug;

- Clay plug uplift did not cause premature termination of suction bucket installation, although consideration should be given to the potential for clay ingress to compromise the efficiency of the pumping system. Uplift disturbed the clay plug upon completion of the installation process, with detachment evident at the clay-sand interface. The potential effect on the in-service performance of the suction bucket requires further investigation.

- Increasing pumping flow rates in clay-over-sand led to larger final penetration depths and faster installation, as well as a reduced clay plug uplift. Higher pumping flow rates may avoid refusal of suction buckets during installation in such profiles.

\section{Data availability}

The data obtained from the centrifuge tests are available from the corresponding author by request. GeoPIV-RG is a free image analysis module for MATLAB designed for geotechnical and structural engineering research applications, available from http://www.geopivrg.com/.

\section{Acknowledgments}

This work forms part of the activities of the Centre for Offshore Foundation Systems (COFS), which is currently supported as a Centre of Excellence by the Lloyd's Register Foundation. Lloyd's Register Foundation helps to protect life and property by supporting engineeringrelated education, public engagement and the application of research. This research is also supported through the Australian Research Council Linkage Project 180100024. The authors are grateful for this support. 
The views presented in this paper represent those of the authors and not necessarily those of their respective employers.

\section{References}

Andersen, K. H., Murff, J. D., Randolph, M. F., Cluckey, E. C., Erbrich, C. T., Jostad, H. P., Hansen, B., Aubeny, C., Sharma, P. and Supachawarote, C. (2005). Suction anchors for deepwater applications. Proc. Int. Symp. Frontiers in Offshore Geotechnics, ISFOG05, Perth, pp. 3-30.

Andersen, K.H., Jostad, H.P. and Dyvik, R. (2008). Penetration resistance of offshore skirted foundations and anchors in dense sand. Journal of Geotechnical and Geoenvironmental Engineering, Vol. 134, No. 1, pp. 106-116.

Bienen, B., Klinkvort, R.T., O’Loughlin, C.D., Zhu, F. and Byrne, B.W. (2018). Suction caisson in dense sand, part I: installation, limiting capacity and drainage. Géotechnique, Vol. 68, No. 11, pp. 937-952, https://doi.org/10.1680/jgeot.16.P.281.

Chow, S. H., A. Roy, M. Herduin, E. Heins, L. King, B. Bienen, C. D. O’Loughlin, C. Gaudin, and M. J. Cassidy. 2019. Characterisation of UWA superfine silica sand, 33. GEO Rep. 18844. Crawley, Australia: Univ. of Western Australia.

Cocjin, M. L., S. M. Gourvenec, D. J. White, and M. F. Randolph. 2014. "Tolerably mobile subsea foundations-Observations of performance." Géotechnique 64 (11): 895-909. https://doi.org/10.1680/geot.14.P.098.

Cotter, O. (2009). The installation of suction caisson foundations for offshore renewable energy structures. $\mathrm{PhD}$ thesis, University of Oxford, UK.

Cotterill, C.J., Phillips, E., James, L., Forsberg, C.F., Tjelta, T.I., Carter, G. and Dove, D. (2017). The evolution of the Dogger Bank, North Sea: a complex history of terrestrial, glacial and marine environmental change. Quaternary Science Reviews, Vol. 171, pp. 136153.

Craig, W. H. \& Chua, K. (1990). Deep penetration of spudcan foundations on sand and clay. Géotechnique, Vol. 40, No. 4, 541-556.

Dewoolkar, M.M., Ko, H.Y., Stadler, A.T. and Astaneh, S.M.F. (1999). A substitute pore fluid for seismic centrifuge modeling. Geotechnical Testing Journal, Vol. 22, No. 3, pp. 196-210.

DOV 2002. Methocel Cellulose ethers. Technical Handbook.

Dove, D., Roberts, D.H., Evans, D.J.A., Tappin, D.R., Lee, J.R., Long, D. and Callard, S.L. (2016). Refining Glacial Statigraphy in the Southern North Sea-New Bathymetric Model Brings Renewed Value to Legacy Seismic. Near Surface Geoscience 2016 - Second Applied Shallow Marine Geophysics Conference. 
Ghazi, N. (2018). World's most powerful wind turbine installed in Aberdeen Bay. https://news.vattenfall.com/en

Haigh, S.K. and Madabhushi, S.P.G. (2014). Discussion of "Performance of a transparent flexible shear beam container for geotechnical centrifuge modelling of dynamic problems by Ghayoomi, Dashti and McCartney". Soil Dynamics and Earthquake Engineering, Vol. 67, pp. 359-362.

Erbrich, C.T. and Tjelta, T.I. (1999). Installation of bucket foundations and suction caissons in sand - geotechnical performance. Proc. Offshore Technology Conference, Houston, USA, OTC-10990.

Houlsby, G.T. and Byrne, B.W. (2005a). Design procedures for installation of suction caissons in clay and other materials. In Proc. of the Institution of Civil Engineers - Geotechnical Engineering, Vol. 158, No. 2, pp. 75-82.

Houlsby, G.T. and Byrne, B.W. (2005b). Design procedures for installation of suction buckets in sand. In Proc. of the Institution of Civil Engineers - Geotechnical Engineering, Vol. 158, No. 3, pp. 135-144.

Lacal-Arántegui, R., Yusta, J.M., Domínguez-Navarro, J.A. (2018). Offshore wind installation: Analysing the evidence behind improvements in installation time. Renewable and Sustainable Energy Reviews, Vol. 92, pp. 133-145.

Ladd, C.C., Foot, R., Ishihara, K., Schlosser, F. and Poulos, H.G. (1977). Stress-deformation and strength characteristics. Proc. Int. Conf. Soil Mech. Found. Engng, Tokyo, Japan. pp. 421-494.

Lee, K.K., Randolph, M. F. and Cassidy, M.J. (2013). Bearing capacity on sand overlying clay soils: a simplified conceptual model. Géotechnique, Vol. 63, No. 15, pp. 1285-1297.

Martin, C. M. and Randolph, M. (2006). Upper-bound analysis of lateral pile capacity in cohesive soil. Géotechnique, Vol. 56, No. 2, pp. 141-145.

Meyerhof, G.G. (1974). Ultimate bearing capacity of footings on sand layer overlying clay. Canadian Geotechnical Journal, Vol. 11, No. 2, pp. 223-229.

Morton, J. P., C. D. O’Loughlin, and D. J. White. 2014. "Strength assessment during shallow penetration of a sphere in clay." Géotech. Lett. 4 (4): 262-266. https://doi.org/10.1680/geolett.14.00049.

O'Beirne, C., C. D. O'Loughlin, and C. Gaudin. 2015. "Soil response in the wake of dynamically installed projectiles.” Géotech. Lett. 5 (3): 153-160. https://doi.org/10.1680/jgele.15.00055.

Offshorewind.biz (2018). https://www.offshorewind.biz/2018/05/28/last-eowdc-turbineinstalled-inter-array-cabling-nearing-completion/ 
Qiu, G. and Grabe, J. (2012). Numerical investigation of bearing capacity due to spudcan penetration in sand overlying clay. Canadian Geotechnical Journal, Vol. 49, No. 12, pp. 1393-1407.

Panayides, S., Powell, T.A., Schrøder, K. (2017). Penetration resistance of suction caissons in layered soils - a case study. Proc. International Conference, Society for Underwater Technology, Offshore Site Investigation and Geotechnics (SUT-OSIG), London, UK, pp. 562-569.

Ragni, R., Bienen, B., Stanier, S.A., O’Loughlin, C. and Cassidy, M.J. (2019). Observations during suction bucket installation in sand. International Journal of Physical Modelling in Geotechnics, https://doi.org/10.1680/jphmg.18.00071.

Randolph, M.F., Jewell, R.J., Stone, K.J.L. and Brown, T.A. (1991). Establishing a new centrifuge facility. Proc. International Conference Centrifuge, Boulder, USA, pp. 3-9.

Randolph, M.F. and Gaudin, C. (2017). Genesis of the national geotechnical centrifuge facility - A 30 year perspective. Australian Geomechanics Journal, Vol. 52, No. 2, pp. 1-14.

Saue, M., Aas, P.M., Andersen, K.H., Solhjell, E. (2017). Installation of suction anchors in layered soils. Proc. International Conference, Society for Underwater Technology, Offshore Site Investigation and Geotechnics (SUT-OSIG), London, UK, pp. 507-515.

Senders, M., Randolph, M.F. and Gaudin, C. (2007). Theory for the installation of suction caissons in sand overlaid by clay. Proc. International Conference, Society for Underwater Technology, Offshore Site Investigation and Geotechnics (SUT-OSIG), London, UK, pp. 429-438.

Senders, M. (2008). Suction caissons in sand as tripod foundations for offshore wind turbines. $\mathrm{PhD}$ thesis, The University of Western Australia, Australia.

Senders, M. and Randolph, M.F. (2009). CPT-based method for the installation of suction buckets in sand. Journal of Geotechnical and Geoenvironmental Engineering (ASCE), Vol. 135, No. 1, pp. 14-25.

Stanier, S.A. and White, D.J. (2013). Improved image-based deformation measurement in the centrifuge environment. Geotechnical Testing Journal, Vol. 36, No. 6, pp. 915-928.

Stanier, S.A., Blaber, J., Take, W.A. and White, D.J. (2015). Improved image-based deformation measurement for geotechnical applications. Canadian Geotechnical Journal, Vol. 53, No. 5, pp. 727-739.

Stewart, D. P. 1992. "Lateral loading of piled bridge abutments due to embankment construction.” Ph.D. thesis, Dept. of Civil Engineering, Univ. of Western Australia.

Sturm H. (2017). Design Aspects of Suction Caissons for Offshore Wind Turbine Foundations. Proc. TC 209 workshop - International Conference on Soil Mechanics and Geotechnical Engineering, Seoul, South Korea, pp. 45-63. 
Tan, T.S. and Scott, R.F. (1985). Centrifuge scaling considerations for fluid-particle systems. Géotechnique, Vol. 35, No. 4, pp. 461-470.

Taylor, R.N. (1987). Discussion of "Tan, T.S. and Scott, R.F. (1985). Centrifuge scaling considerations for fluid-particle systems." Géotechnique, Vol. 37, No. 1, pp. 131-133.

Teh, K.L., Cassidy, M.J., Leung, C.F., Chow, Y.K., Randolph, M.F., Quah, C.K. (2008). Revealing the bearing failure mechanisms of a penetrating spudcan through sand overlaying clay. Géotechnique, Vol. 58, No. 10, pp 793-804.

Teng, Y., Stanier, S.A. and Gourvenec, S.M. (2017). Synchronised multi-scale image analysis of soil deformations. International Journal of Physical Modelling in Geotechnics, Vol. 17, No. 1, pp. 53-71.

Watson, P.G., Gaudin, C., Senders, M. and Randolph, M.F. (2006). Installation of suction caisson in layered soil. In Proc. In Proc. International Conference on Physical Modelling in Geotechnics, Vol. 1, pp. 685-692.

Tran, M.N. (2005). Installation of suction buckets in dense sand and the influence of silt and cemented layers. PhD thesis, The University of Sydney, Australia.

Tran, M.N., Randolph, M.F. and Airey, D.W. (2007). Installation of suction caissons in sand with silt layers. Journal of Geotechnical and Geoenvironmental Engineering, Vol. 133, No. 10, pp. 1183-1191.

Zhu, F. (2018). Suction caisson foundations for offshore wind energy installations in layered soils. $\mathrm{PhD}$ thesis, The University of Western Australia, Australia. 
Table 1: Summary of experimental program.

\begin{tabular}{|c|c|c|c|c|c|}
\hline Test & $\begin{array}{c}\text { Top } \\
\text { layer }\end{array}$ & $\begin{array}{c}\text { Top layer thickness } \\
\text { Target } \mid \text { Actual } \\
(\boldsymbol{h} / \mathbf{L})\end{array}$ & $\begin{array}{c}\text { Relative } \\
\text { density } \\
\text { of sand } \\
\boldsymbol{D}_{\boldsymbol{r}}(\mathbf{\%})\end{array}$ & $\begin{array}{c}\text { Undrained } \\
\text { shear strength } \\
\text { of clay* } \\
\boldsymbol{s}_{\mathbf{u}}(\mathbf{k P a})\end{array}$ & $\begin{array}{c}\text { Pumping flow } \\
\text { rate }\end{array}$ \\
\hline SoC_1 & Sand & $0.6 \mid 0.62$ & 100 & $\sim 30$ & N/A (Jacked) \\
\hline SoC_2 & Sand & $0.6 \mid 0.59$ & 100 & $\sim 30$ & 235.6 (Med) \\
\hline CoS_1 & Clay & $0.2 \mid 0.2$ & 99 & $\sim 12.8$ & N/A (Jacked) \\
\hline CoS_2 & Clay & $0.2 \mid 0.19$ & 91 & $\sim 12.8$ & 117.8 (Low) \\
\hline CoS_3 & Clay & $0.2 \mid 0.19$ & 91 & $\sim 12.8$ & 235.6 (Med) \\
\hline CoS_4 & Clay & $0.2 \mid 0.17$ & 94 & $\sim 12.8$ & 1178.1 (High) \\
\hline CoS_5 & Clay & $0.4 \mid 0.36$ & 87 & $\sim 14.8$ & 235.6 (Med) \\
\hline CoS_6 & Clay & $0.6 \mid 0.56$ & 100 & $\sim 16.2$ & 235.6 (Med) \\
\hline
\end{tabular}

* Estimated according to Ladd et al. (1997) 
Table 2: Silica sand and kaolin clay properties (Data from Tran 2005, Chow et al. 2019, Stewart 1992).

\begin{tabular}{|c|c|c|c|c|c|c|}
\hline \multicolumn{7}{|c|}{ Fine silica sand } \\
\hline $\begin{array}{c}\text { Specific } \\
\text { gravity, } G_{\mathrm{s}}\end{array}$ & $\begin{array}{l}\text { Mean } \\
\text { particle } \\
\text { size, } d_{50} \\
(\mathbf{m m})\end{array}$ & $\begin{array}{c}\text { Minimum } \\
\text { dry } \\
\text { density, } \\
\rho_{\text {min }} \\
\left(\mathbf{k g} / \mathbf{m}^{3}\right)\end{array}$ & $\begin{array}{c}\text { Maximum } \\
\text { dry } \\
\text { density, } \\
\rho_{\max } \\
\left(\mathbf{k g} / \mathbf{m}^{3}\right)\end{array}$ & $\begin{array}{c}\text { Minimum } \\
\text { void ratio, } \\
e_{\min }(-)\end{array}$ & $\begin{array}{c}\text { Maximum } \\
\text { void ratio, } \\
e_{\max }(-)\end{array}$ & $\begin{array}{l}\text { Permeability } \\
\text { (water } \\
\text { saturated), } k_{\mathrm{w}} \\
(\mathrm{m} / \mathrm{s})\end{array}$ \\
\hline 2.67 & 0.18 & 1497 & 1774 & 0.505 & 0.784 & $\sim 1.0 \times 10^{-4}$ \\
\hline \multicolumn{7}{|c|}{ Kaolin clay } \\
\hline $\begin{array}{c}\text { Specific } \\
\text { gravity, } G_{\mathrm{s}}\end{array}$ & $\begin{array}{c}\text { Liquid } \\
\text { Limit, LL }\end{array}$ & $\begin{array}{c}\text { Plastic } \\
\text { Limit, PL }\end{array}$ & $\begin{array}{c}\text { Void ratio } \\
\text { at } p^{\prime}=1 \mathrm{kPa} \\
\text { on CSL, } \\
e_{\text {cs }}(-)\end{array}$ & $\begin{array}{c}\text { Slope } \\
\text { NCL, } \\
\quad \lambda\end{array}$ & $\begin{array}{c}\text { Slope URL, } \\
\kappa\end{array}$ & $\begin{array}{c}\text { Permeability } \\
\text { (water } \\
\text { saturated) } \\
k_{\mathrm{w}}(\mathrm{m} / \mathrm{s})\end{array}$ \\
\hline 2.6 & $61 \%$ & $27 \%$ & 2.14 & 0.205 & 0.044 & $\sim 1.7 \times 10^{-9}$ \\
\hline
\end{tabular}


Table 3: Summary of experimental results.

\begin{tabular}{|c|c|c|c|c|c|c|c|}
\hline Test & $\begin{array}{c}\text { Self-weight } \\
\text { penetration } \\
\text { z/L (-) }\end{array}$ & $\begin{array}{r}V_{\mathrm{s}-\mathrm{w}} / \mathrm{A}^{*} \\
(\mathrm{kPa})\end{array}$ & $\begin{array}{c}\text { Final } \\
\text { penetration } \\
z / L(-)\end{array}$ & $\begin{array}{c}\text { Internal } \\
\text { plug heave } \\
h_{\text {plug }} / L(-)\end{array}$ & $\begin{array}{c}\text { Skirt } \\
\text { contribution } \\
\text { to plug } \\
\text { heave } \\
h_{\text {skirt }} / L(-)\end{array}$ & $\begin{array}{c}\text { Dilation } \\
\text { contribution } \\
\text { to plug } \\
\text { heave } \\
h_{\mathrm{dil}} / L(-)\end{array}$ & Comment \\
\hline SoC_1 & $\begin{array}{c}\mathrm{N} / \mathrm{A} \\
\text { (Jacked) }\end{array}$ & $\begin{array}{c}\mathrm{N} / \mathrm{A} \\
(\text { Jacked) }\end{array}$ & $1.11^{1}$ & -0.13 & N/A & N/A & $\begin{array}{l}\text { Final penetration, } \mathrm{z} / \mathrm{L}>1 \text { due to significant } \\
\text { compression of the bottom clay layer }\end{array}$ \\
\hline SoC_2 & 0.2 & 99.0 & $1.19^{1}$ & -0.23 & N/A & N/A & \\
\hline CoS_1 & $\begin{array}{c}\mathrm{N} / \mathrm{A} \\
\text { (Jacked) }\end{array}$ & $\begin{array}{c}\mathrm{N} / \mathrm{A} \\
\text { (Jacked) }\end{array}$ & 0.95 & 0.05 & 0.09 & -0.04 & \\
\hline CoS_2 & 0.3 & 357.3 & $0.70^{2}$ & 0.14 & 0.10 & 0.04 & $\begin{array}{l}\text { Full installation not achieved due to } \\
\text { insufficient suction generation at this low } \\
\text { pumping rate }\end{array}$ \\
\hline CoS_3 & 0.3 & 384.3 & $0.80^{3}$ & 0.17 & 0.12 & 0.05 & $\begin{array}{l}\text { Final penetration }+ \text { internal plug heave, } \mathrm{z} / \mathrm{L} \\
+ \text { hplug } / \mathrm{L}<1 \text { due to clay plug fracture and } \\
\text { minor water gap at the clay-sand interface }\end{array}$ \\
\hline CoS_4 & 0.3 & 303.4 & $0.72^{4}$ & 0.14 & 0.10 & 0.04 & $\begin{array}{l}\text { Full installation not achieved due to } \\
\text { sudden failure of the soft sealant at the } \\
\text { model-window interface }\end{array}$ \\
\hline CoS_5 & 0.5 & 438.7 & $0.86^{5}$ & 0.13 & 0.11 & 0.02 & $\begin{array}{l}\text { Final penetration }+ \text { internal plug heave, } \mathrm{z} / \mathrm{L} \\
+ \text { hplug } / \mathrm{L}<1 \text { due to minor water gap at } \\
\text { the clay-sand interface }\end{array}$ \\
\hline CoS_6 & 0.7 & 906.4 & 0.92 & 0.09 & 0.10 & -0.01 & \\
\hline
\end{tabular}

$\mathrm{A}=\left(\pi D_{\mathrm{i}}^{2} / 8\right)$, the internal plan area of the half suction bucket 
Figure 1: Schematic representation of suction bucket installation in a) permeable soil with underlying impermeable layer, and b) in permeable soil overlain by an impermeable layer.

Figure 2: Centrifuge experimental apparatus: a) overview, b) half-model bucket at PIV window, c) macro-camera view (with micro-camera field of view shown).

Figure 3: Representative cone penetration test (CPT) profiles for sand-over-clay (SoC_2, gray) and clay-over-sand (CoS_6, black). (b, RHS) shows an enlarged view of (a, LHS). Note: Clay-sand interfaces reported at actual depth (see Table 1).

Figure 4: Total shear strain $\gamma_{\mathrm{s}}(\%)$ (LHS; a,b,c) and total volumetric strain $\varepsilon_{\mathrm{v}}(\%)$ (RHS, compression positive; d,e,f) contours during jacked installation (SoC_1) at increasing normalised depth $z$ PIV $/ L=0.30(\mathrm{a}, \mathrm{d}) ; 0.60(\mathrm{~b}, \mathrm{e}) ; 0.90(\mathrm{c}, \mathrm{f})$.

Figure 5: Total shear strain (\%) (LHS; a,b,c) and total volumetric strain (\%) (RHS; d,e,f) contours during suction-assisted installation ( $\left.\mathrm{SoC}_{2} 2\right)$ at increasing normalised depth $z$ PIV $/ L=0.30$ (a,d); 0.60 (b,e); 0.90 (c,f).

Figure 6: (a) Normalised suction pressure ( $p$ equivalent to $p_{1}$ of Figure 1), and (b) normalised penetration rate profiles for SoC_2. Note: Sand-clay interface reported at actual depth (see Table 1).

Figure 7: Total shear strain (\%) contours during suction-assisted installation (SoC_2) at normalised depth $z$ PIV $/ L=0.90$; obtained with 'macro' camera (to fully capture the mechanism) images.

Figure 8: Total shear strain (\%) contours during jacked installation $\left(\mathrm{SoC}_{-} 1\right)$ at normalised depth $z$ PIV $/ L=0.90$; obtained with 'macro' camera (to fully capture the mechanism) images.

Figure 9: Normalised resultant displacement contours during jacked installation in test CoS_1 at increasing normalised depth $z \operatorname{PIV} / L=0.15$ (a); 0.30 (b); 0.45 (c); 0.60 (d); 0.75 (e).

Figure 10: Normalised resultant displacement (LHS) and total shear strain (\%) (RHS) contours during suction-assisted installation in test CoS_3 $\left(h_{\text {clay }}=0.2 L, q_{\text {pump }}=235.6 \mathrm{~mm}^{3} / \mathrm{s}\right)$ at increasing normalised depth $z$ PIV $/ L=0.45$ (a-d); 0.60 (b-e); 0.75 (c-f).

Figure 11: (a) Normalised suction pressure ( $p$ equivalent to $p_{1}$ of Figure 1), and (b) normalised penetration rate profiles for clay-over-sand $(\mathrm{CoS})$ tests.

Note: Clay-sand interfaces reported at actual depth (see Table 1).

Figure 12: Total volumetric strain (\%) contours during suction-assisted installation in test CoS_3 at increasing normalised depth $z$ PIV $/ L=0.45$ (a-d); 0.60 (b-e); 0.75 (c-f).

Figure 13: Normalised resultant displacement contours during suction-assisted installation at normalised depth $z \mathrm{PIV} / L=0.60$ for increasing pumping flow rate: (a) $117.8 \mathrm{~mm}^{3} / \mathrm{s}\left(\mathrm{CoS} \_2\right)$; (b) $235.6 \mathrm{~mm}^{3} / \mathrm{s}(\mathrm{CoS} 3)$; (c) $1178.1 \mathrm{~mm}^{3} / \mathrm{s}(\mathrm{CoS} 4)$.

Figure 14: Normalised resultant displacement contours during suction-assisted installation at normalised depth $z$ PIV $/ L=0.75$ for increasing clay thickness $h_{\text {clay }} / L$ : (a) 0.2 (CoS_3); (b) 0.4 (CoS_5); (c) 0.6 (CoS_6). 


\section{APPENDIX}

Figure A1: Final soil plug heave in test CoS_1 (jacked) at $z_{\text {fin }} / L=0.95$

Figure A2: Complete propagation of the fracture at the sand-clay interface in test CoS_3 (medium pumping flow rate) during suction-assisted installation at $z / L=0.46$.

Figure A3: Opening of a fluid channel along the RHS skirt in test CoS_3 (medium pumping flow rate) during suction-assisted installation at $z / L \sim 0.6$.

Figure A4: Final soil plug heave in test CoS_3 (medium pumping flow rate) at $z \mathrm{fin} / L=0.8$

Figure A5: Direct contact between clay plug and valve inlet causing interruption of the flow during suction-assisted installation in test CoS_2 (low pumping flow rate) at $z / L=0.66$.

Figure A6: Fluid mixed with clay appears above the clay plug during suction-assisted installation in test CoS_5 at $z / L=0.65$.

Figure A7: Complete propagation of the fracture at the sand-clay interface in test CoS_5 (medium pumping flow rate) during suction-assisted installation at $z / L=0.76$.

Figure A8: Contact between clay plug and bucket lid at the end of suction-assisted installation in test CoS_5 (medium pumping flow rate) at $z / L=0.86$. 

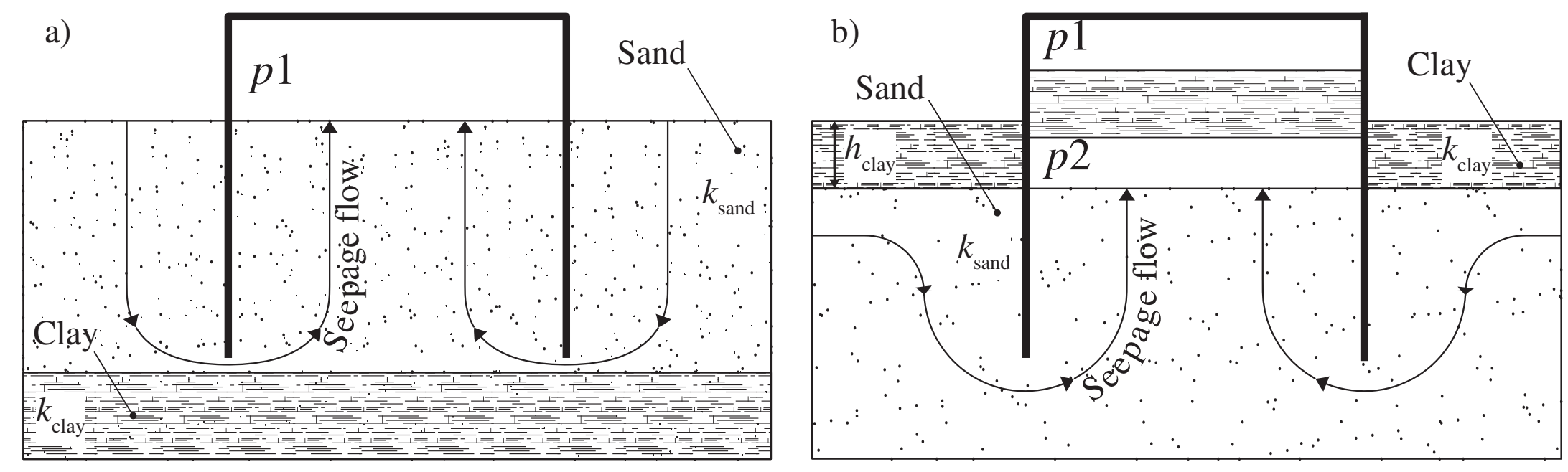

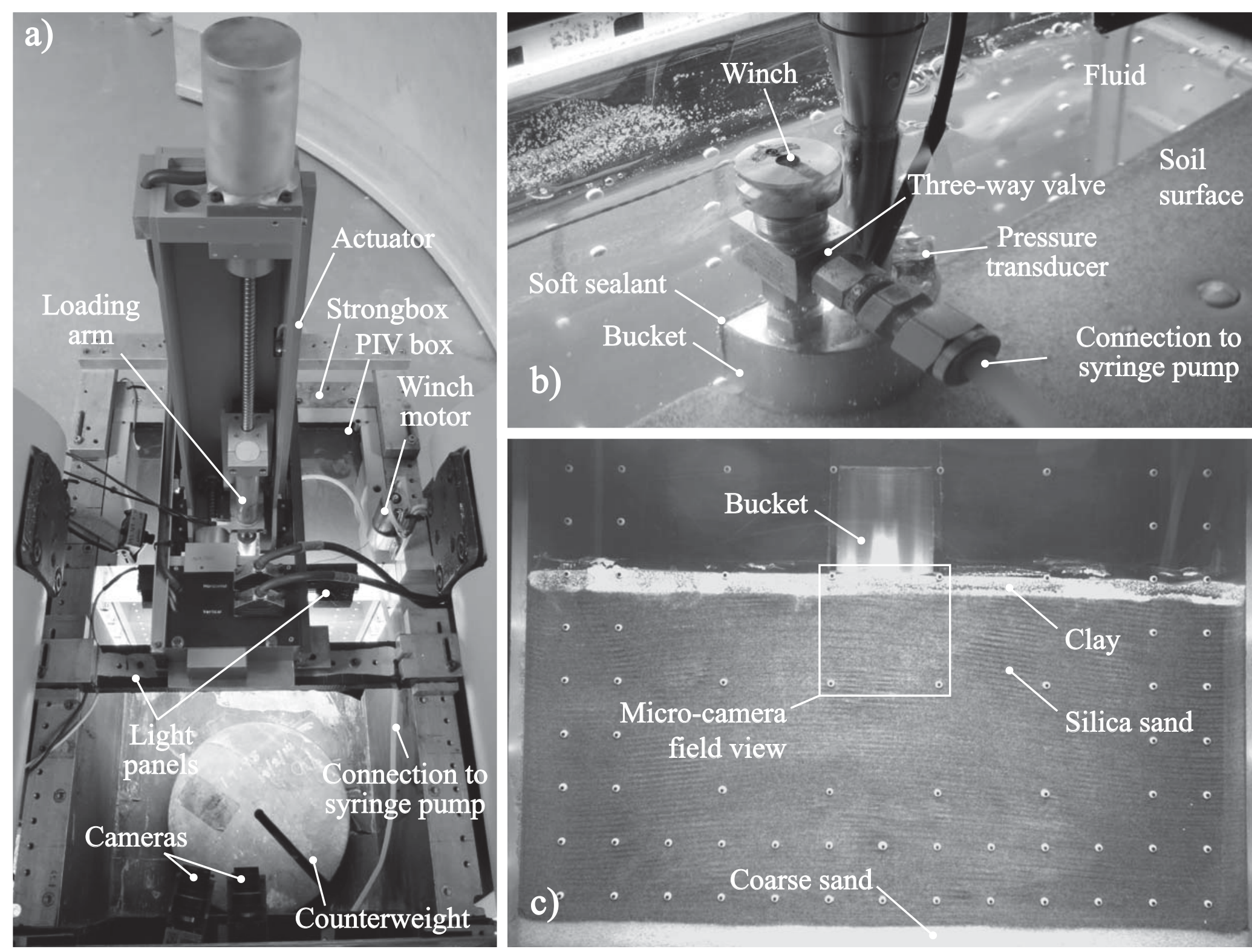


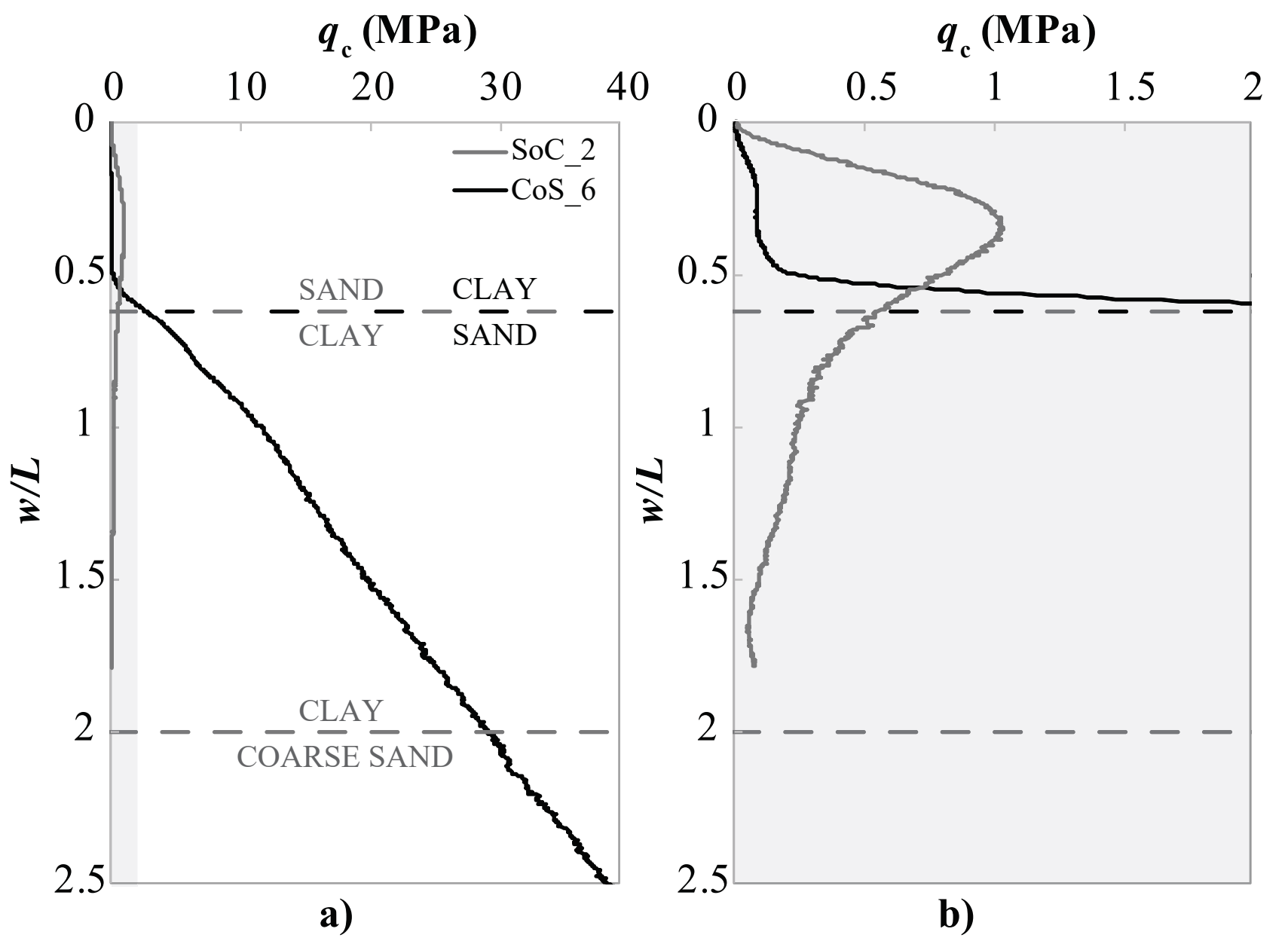



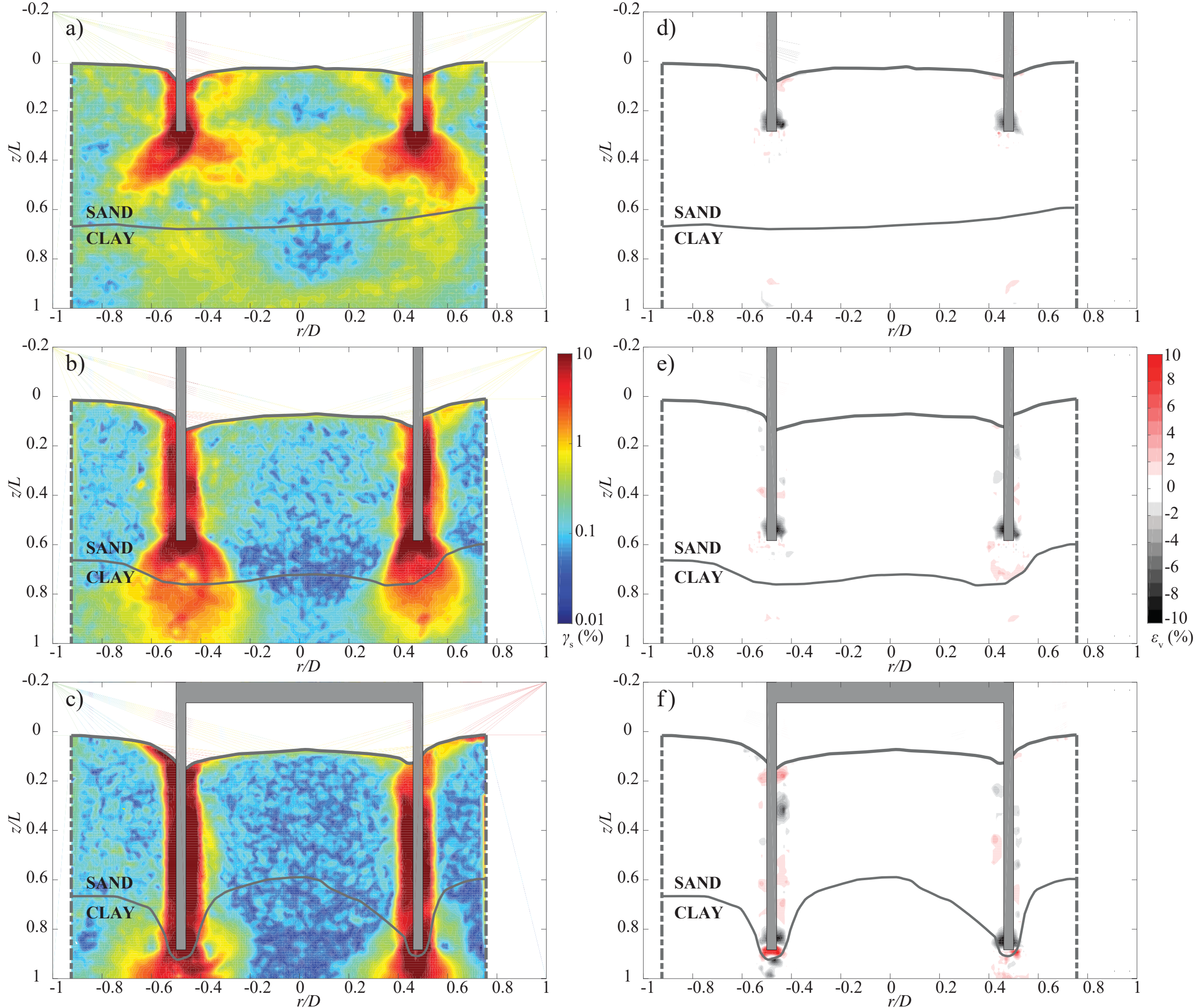

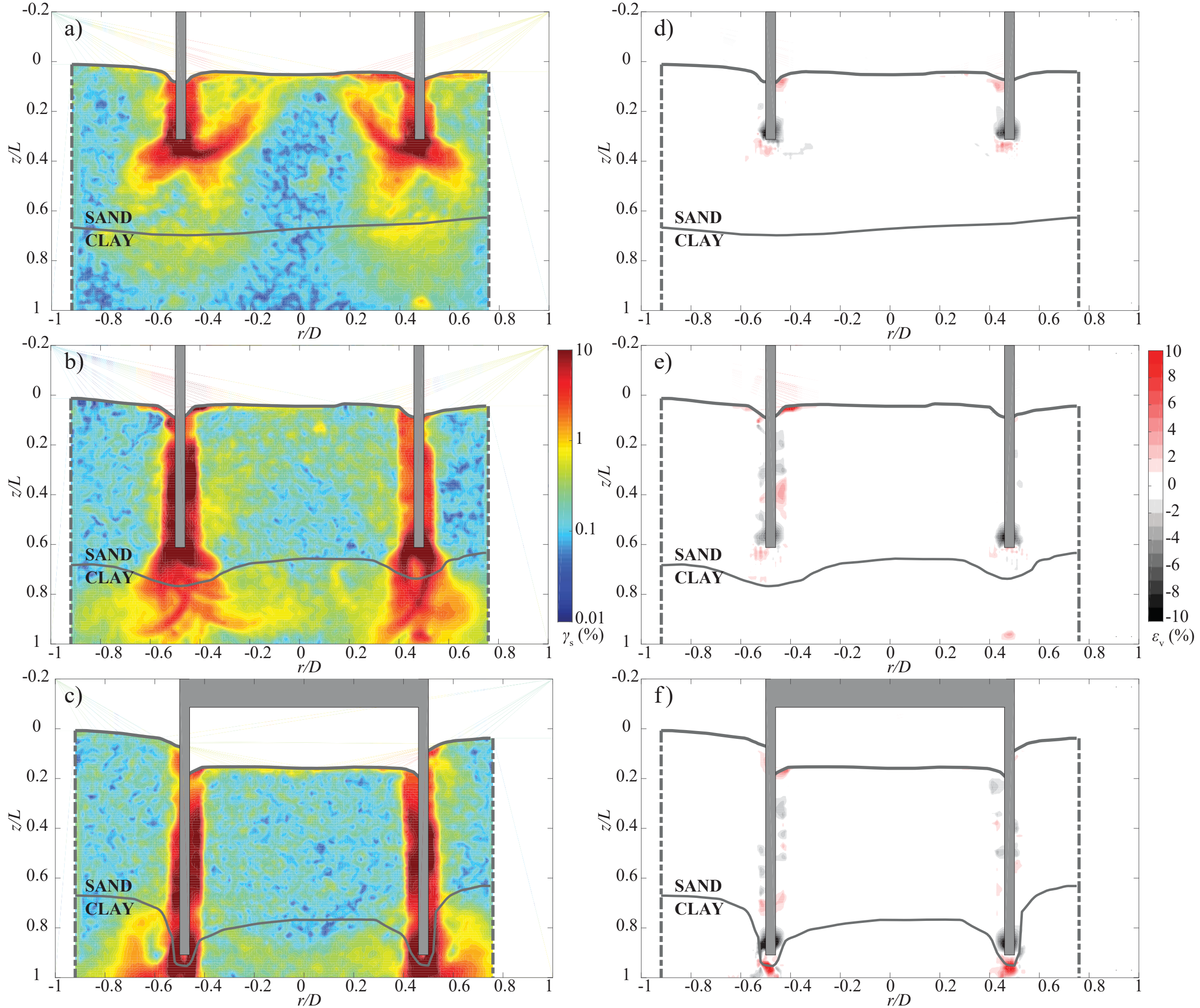


$$
p / \gamma_{\mathrm{s}}^{\prime} D
$$

$(\dot{z} A)_{\text {bucket }} / q_{\text {pump }}$

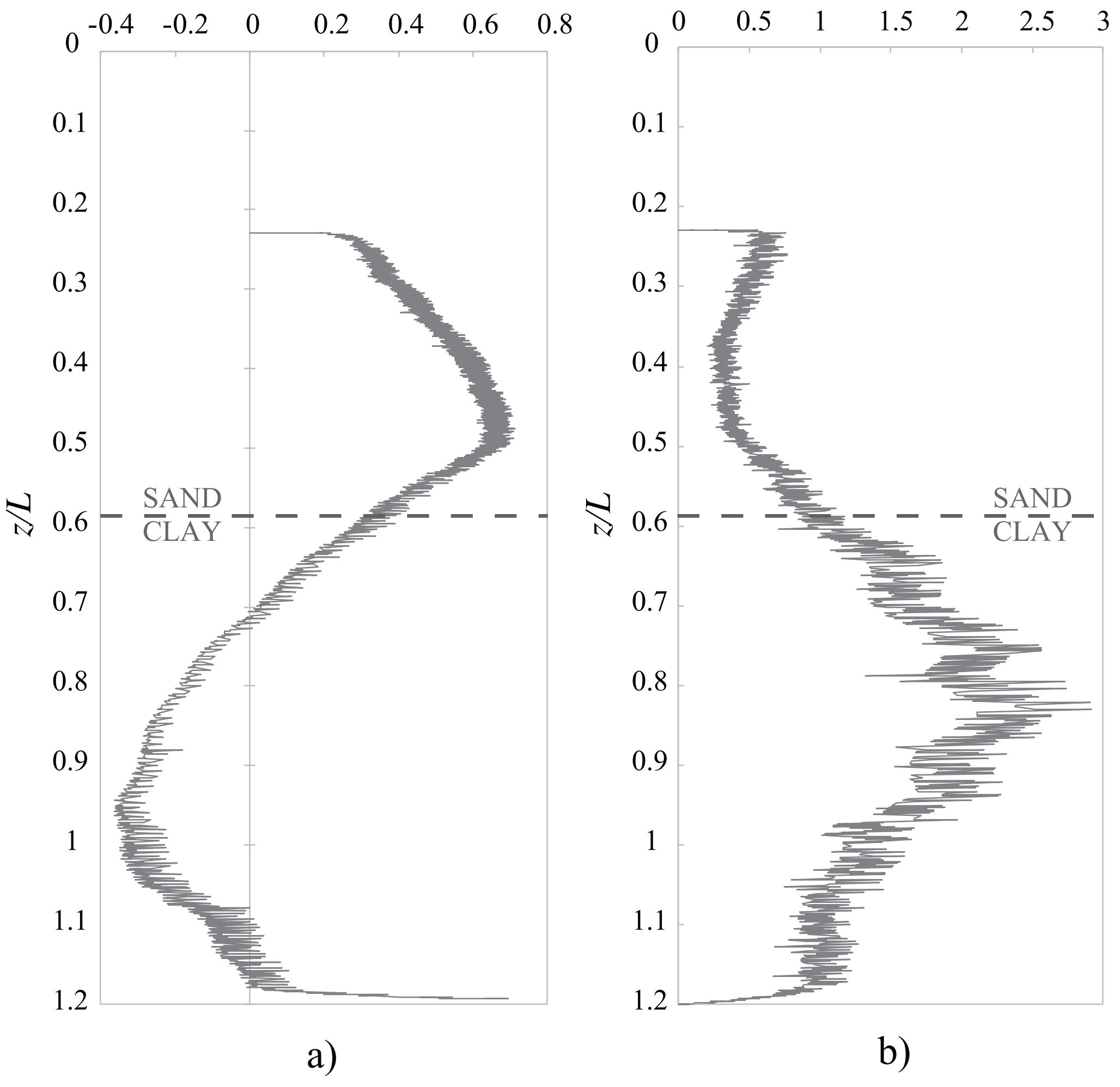




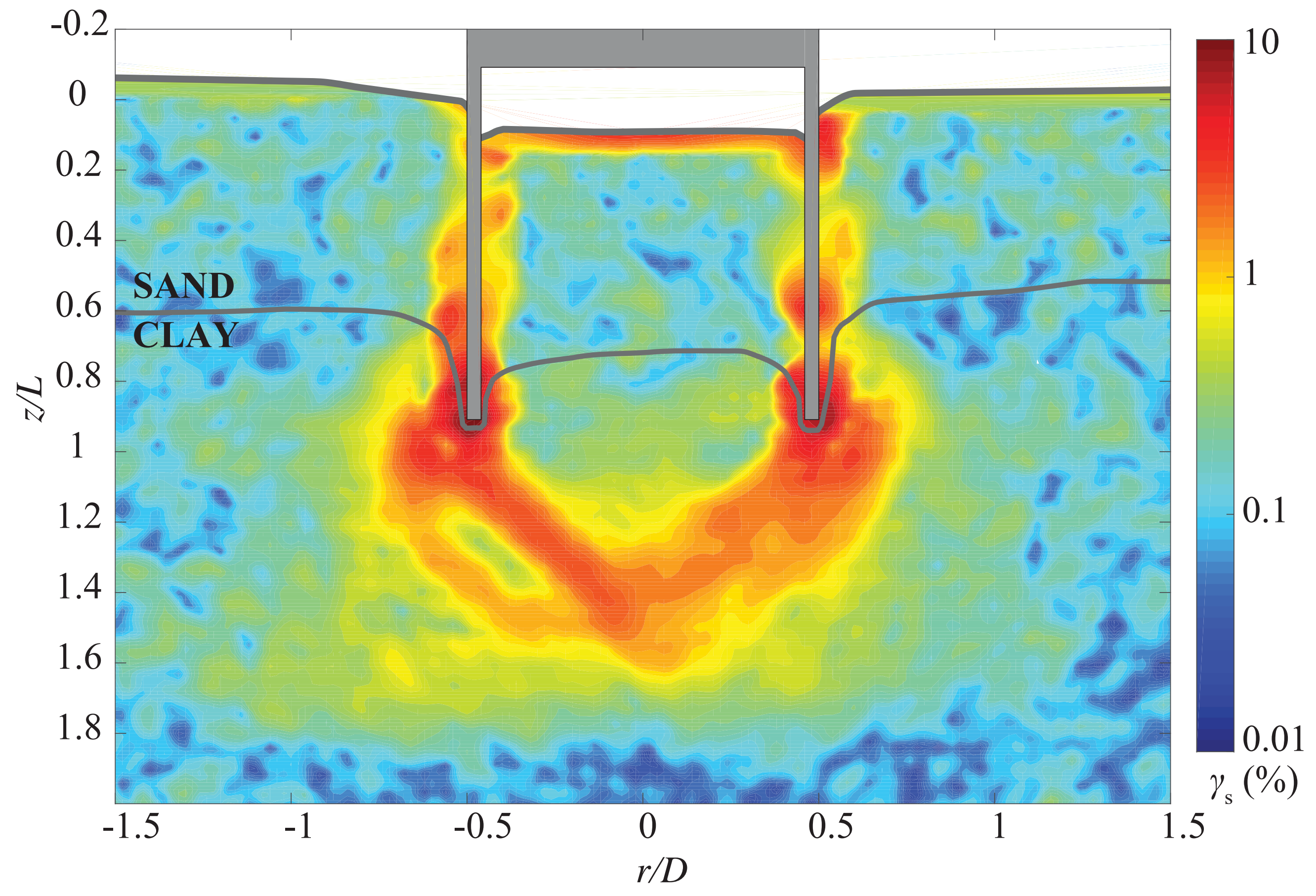




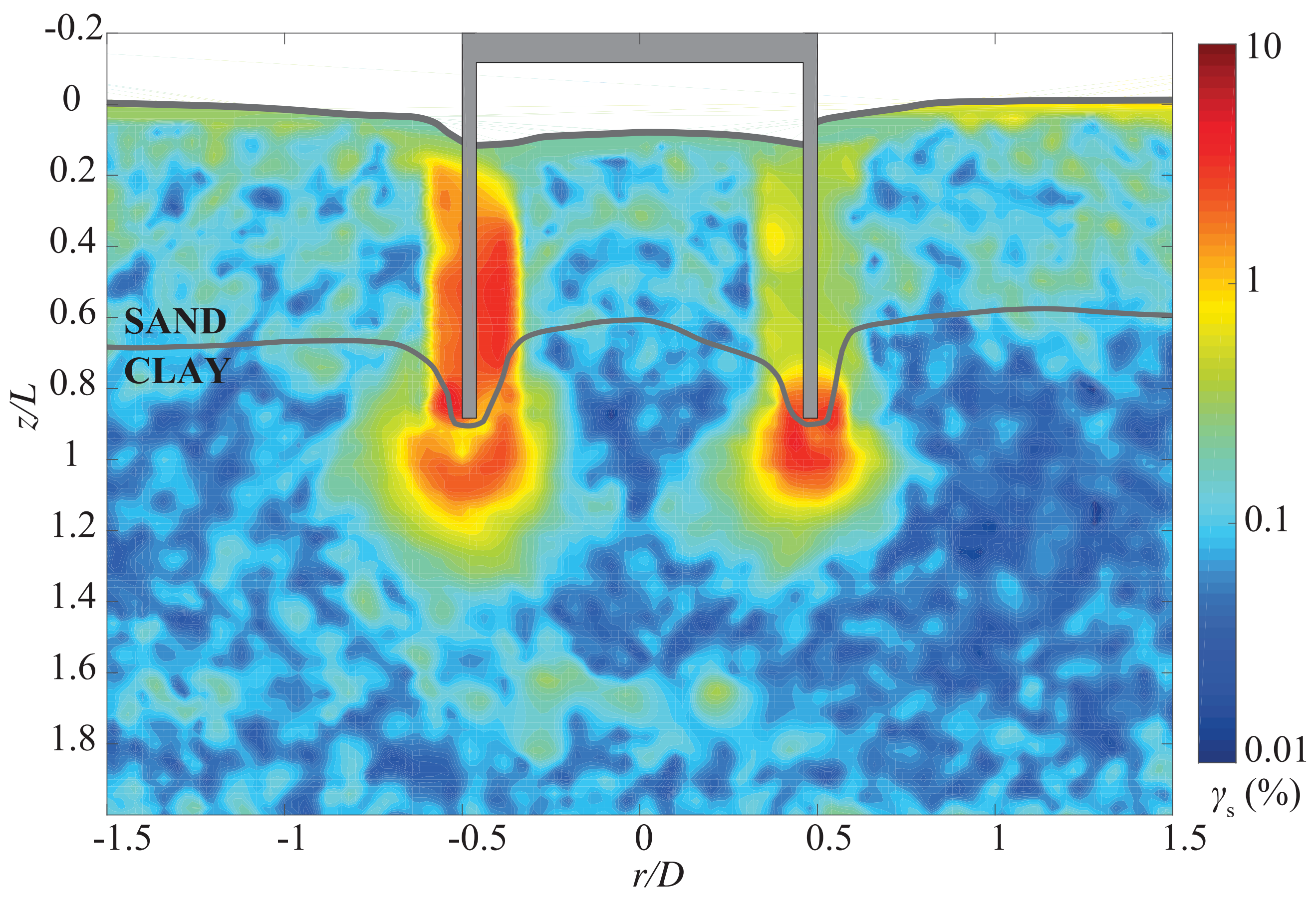



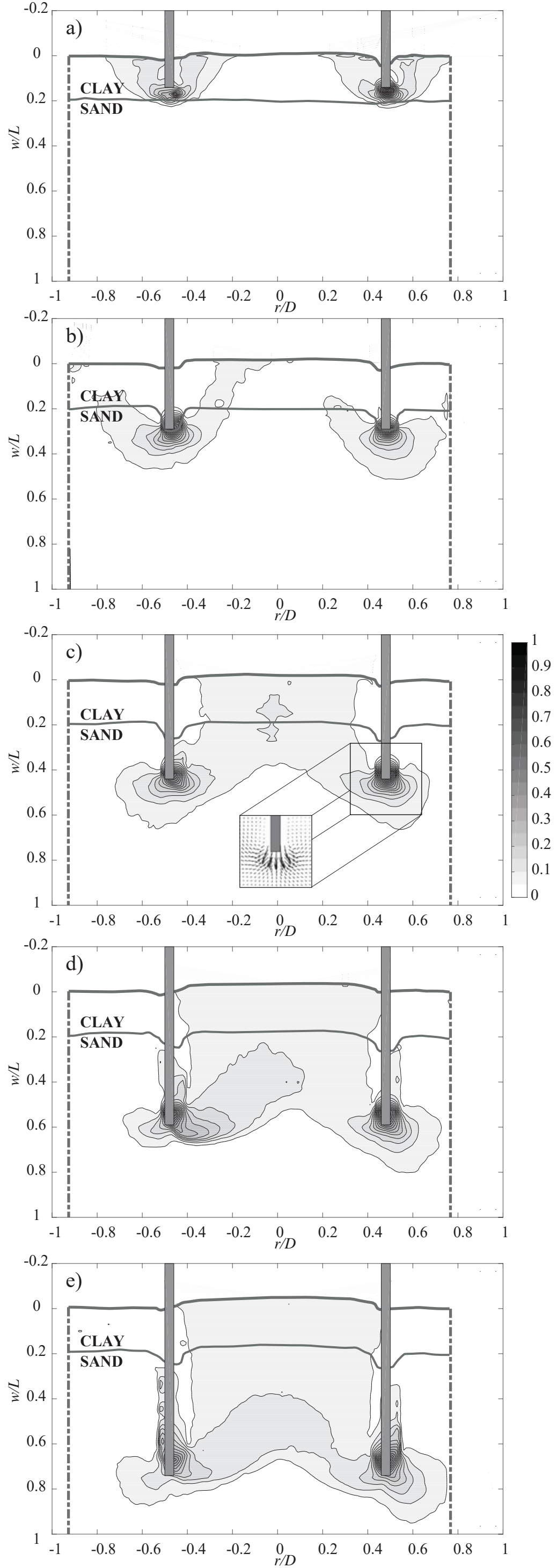


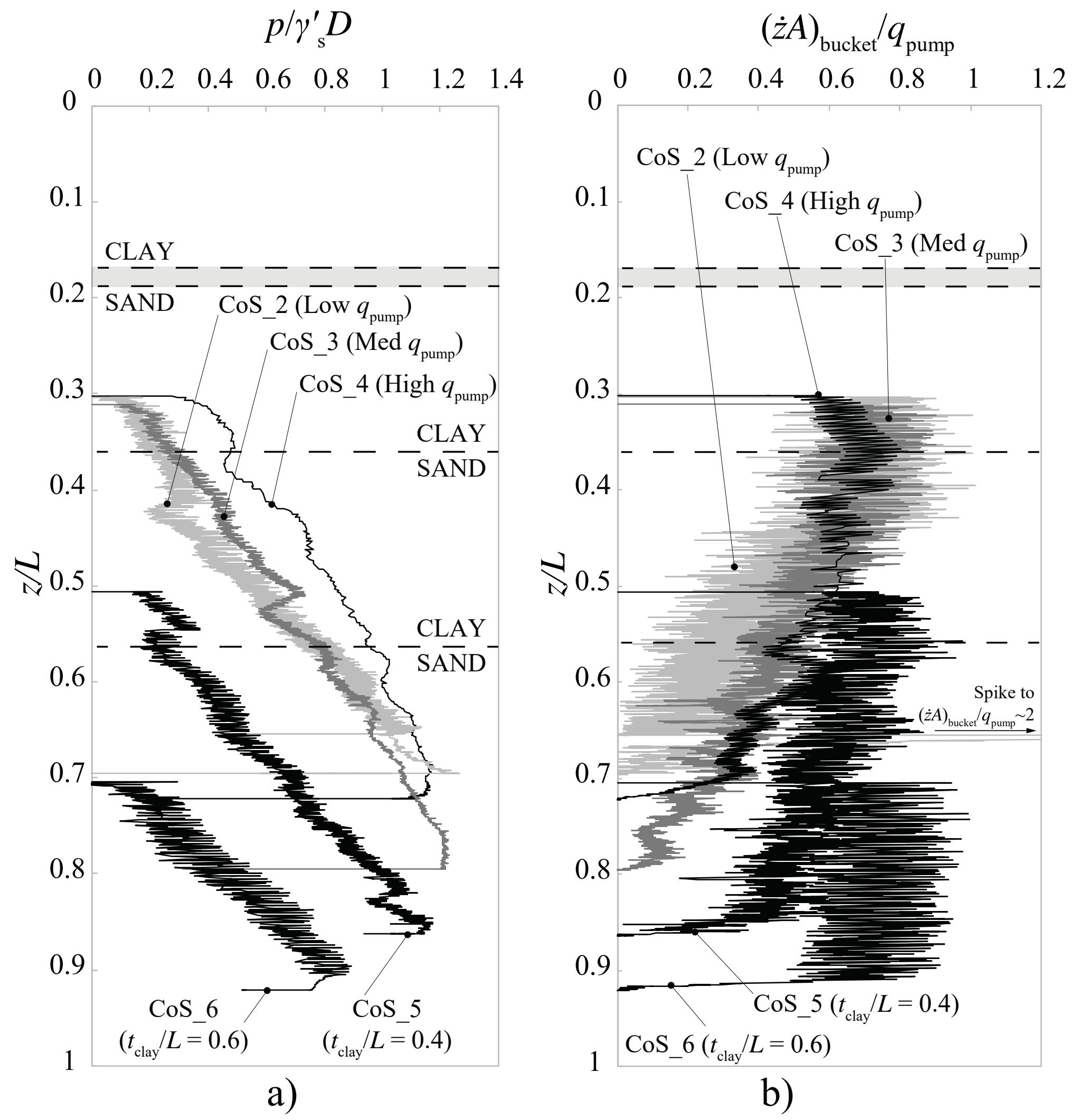



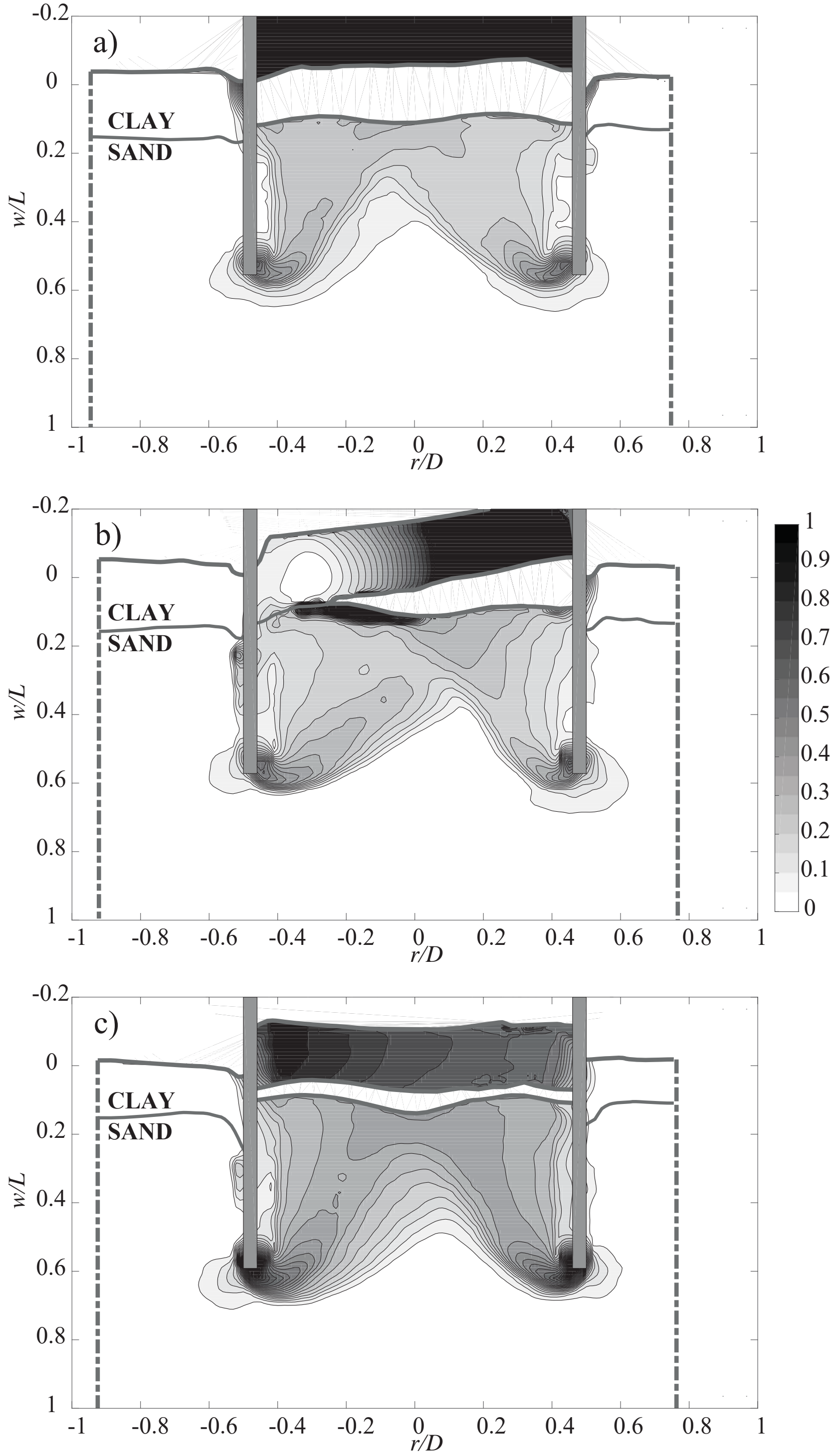

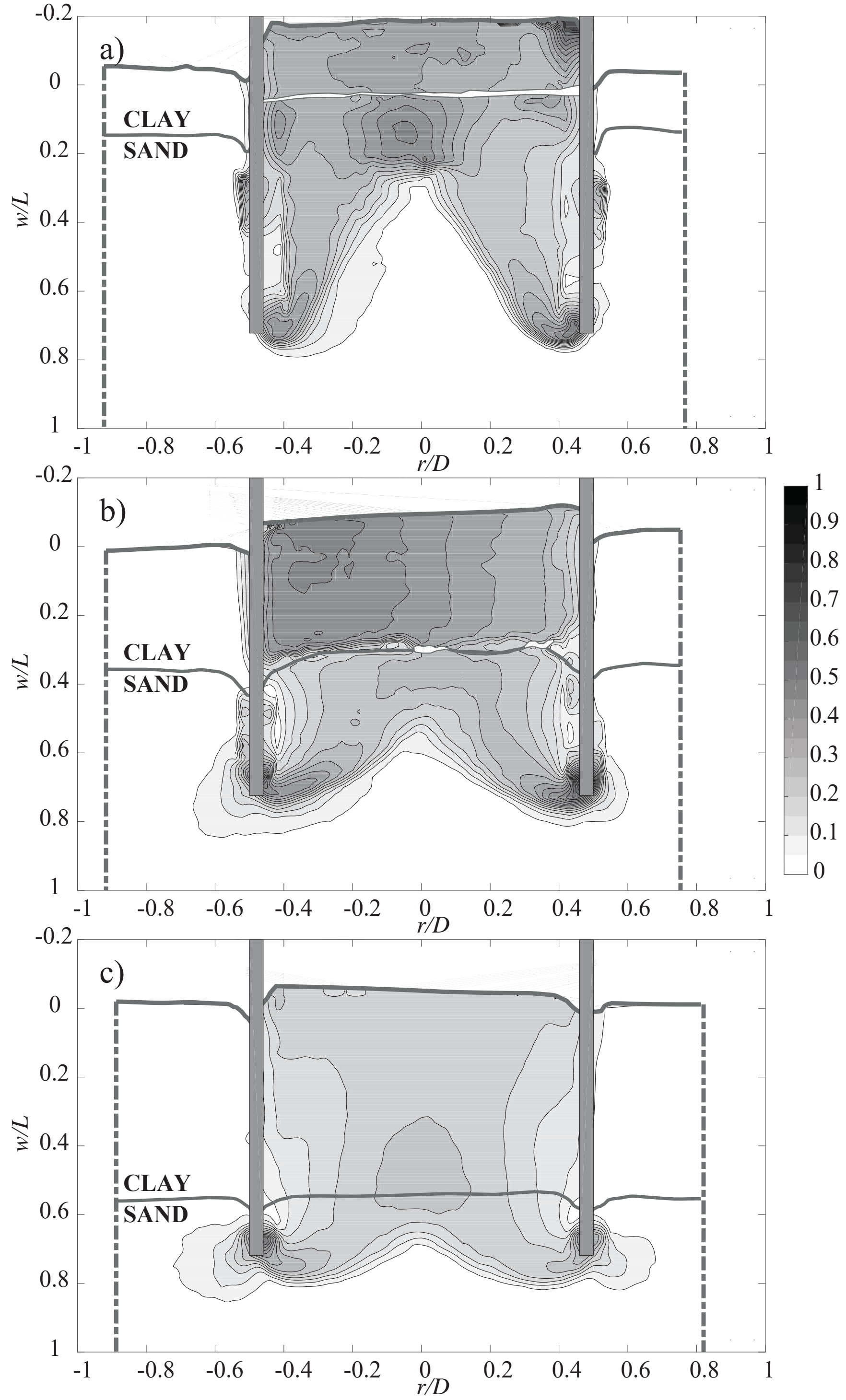
o

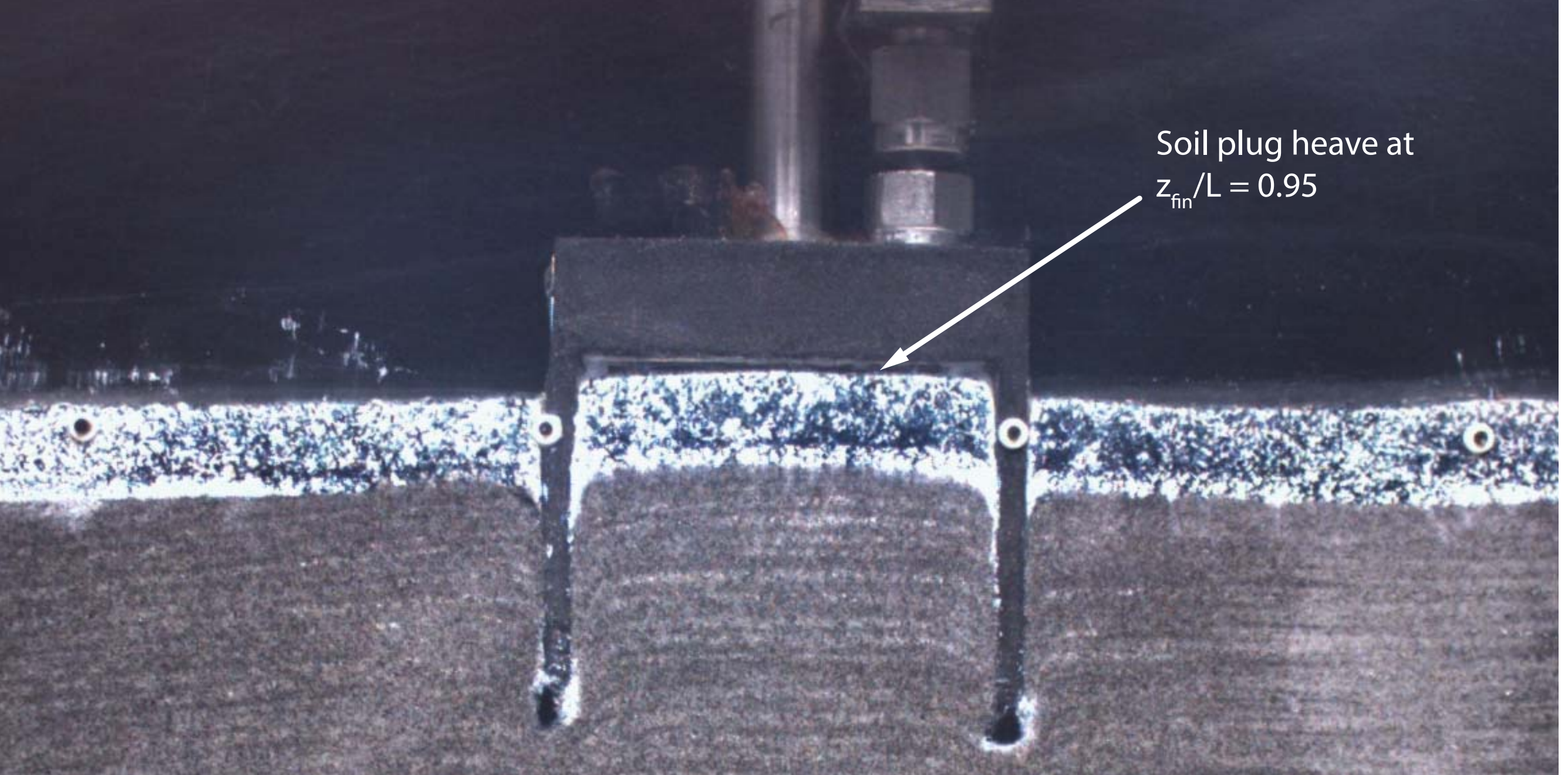

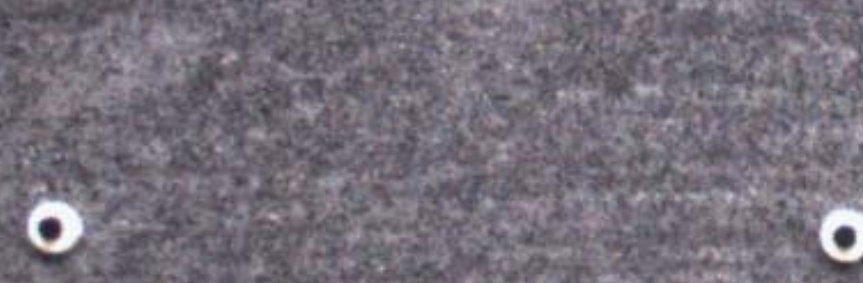

PIV Suction bucket: Macro camera view

Test: $\operatorname{CoS} 1$ (jacked)

\section{(.)}
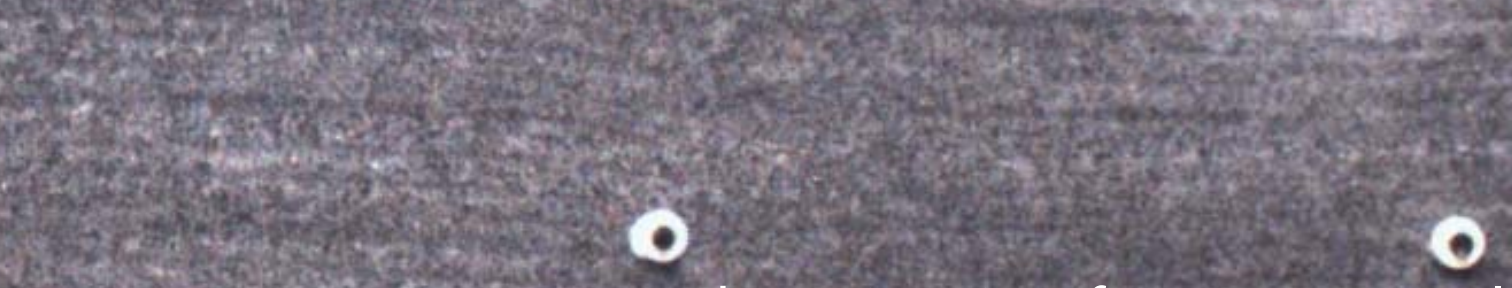

The University of Western Australia National Geotechnical Centrifuge Facility 


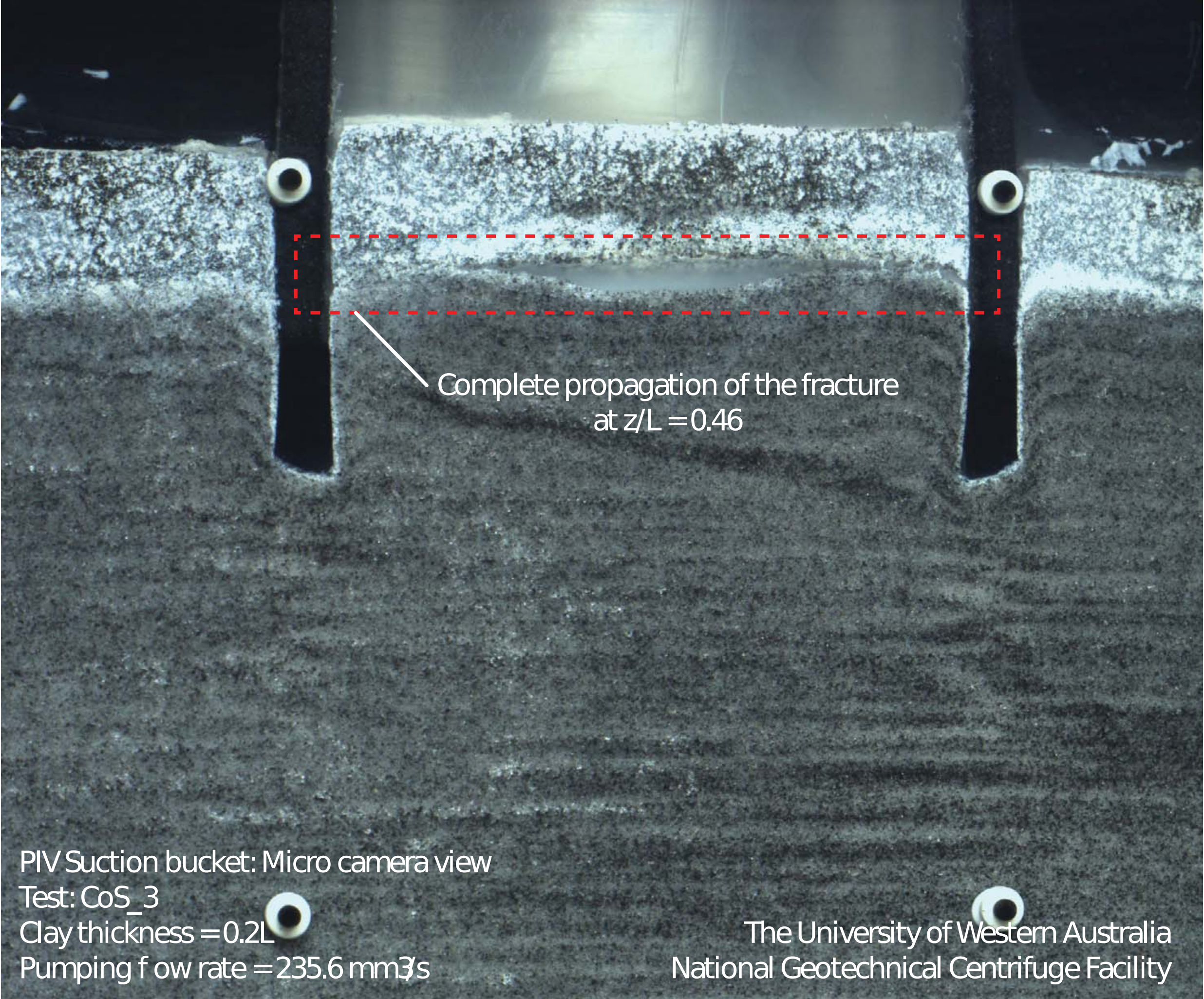




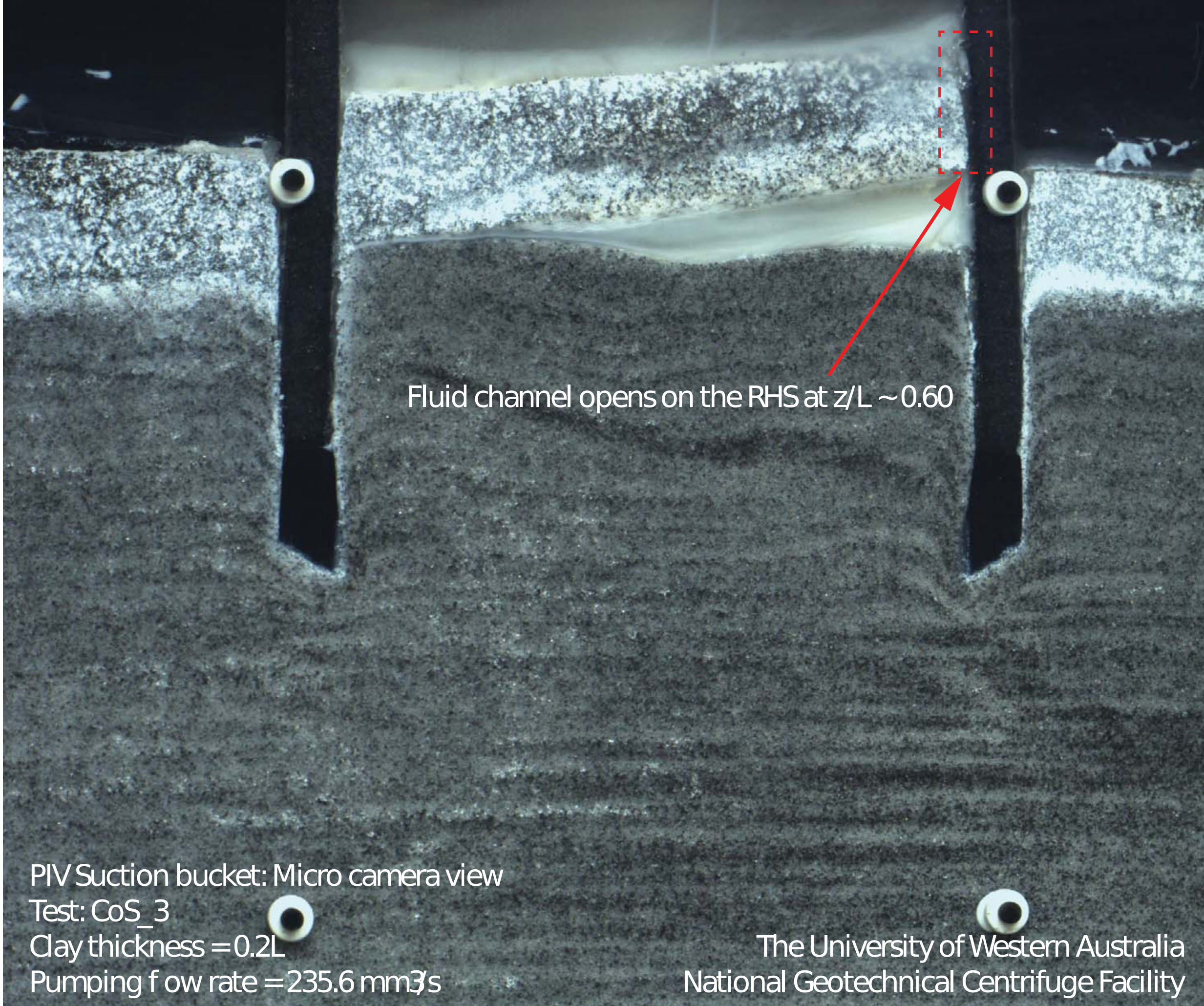




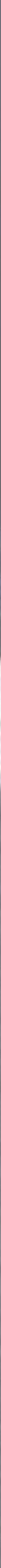




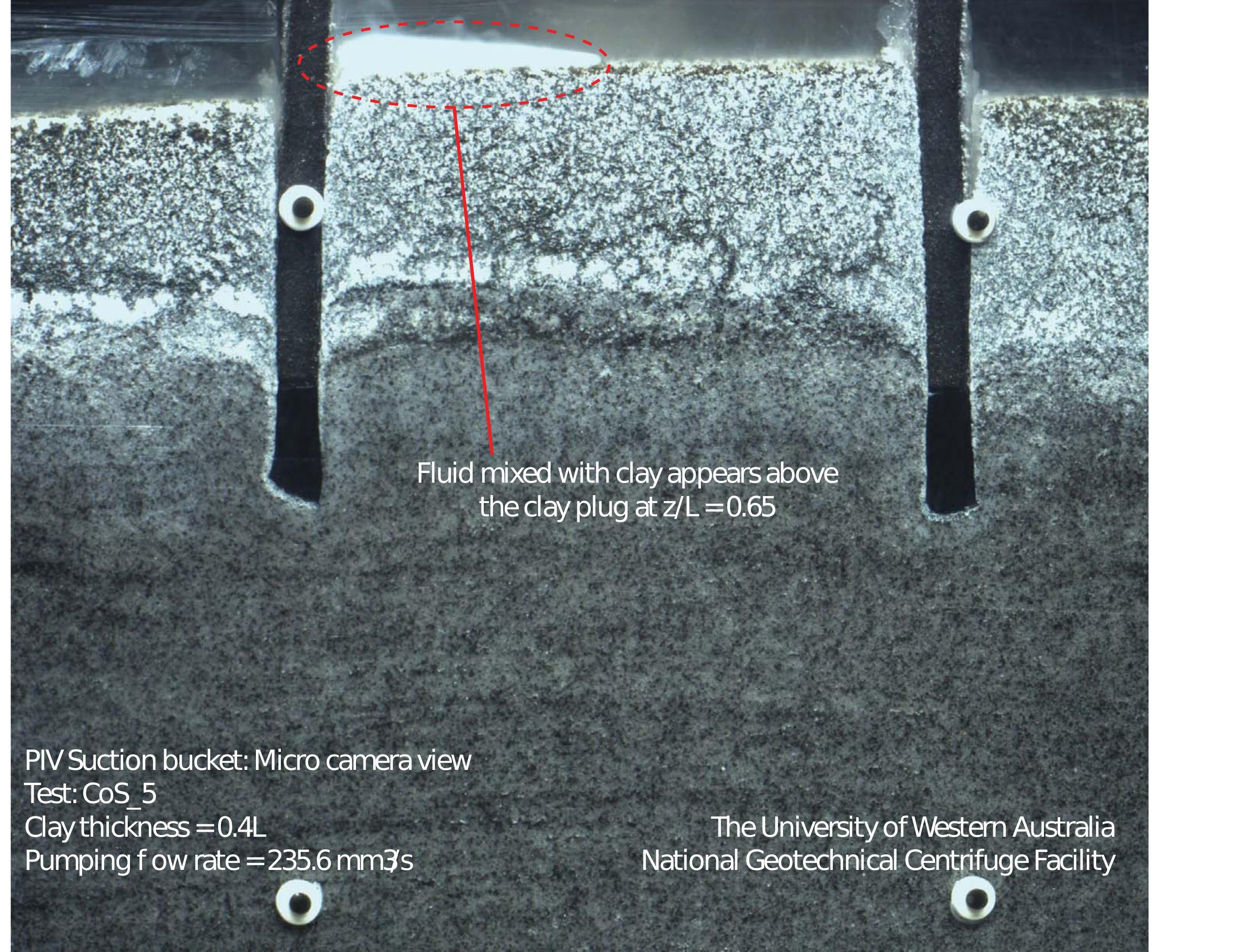


